Supplementary Information

\title{
Surface-Textured Mixed-Metal-Oxide Nanocrystals as Efficient Catalysts for ROS Production and Biofilm Eradication.
}

Nitee Kumari, ${ }^{1,4}$ Sumit Kumar, ${ }^{2,4}$ Mamata Karmacharya,${ }^{2}$ Sateesh Dubbu, ${ }^{1}$ Taewan Kwon, ${ }^{1}$ Varsha Singh, ${ }^{3}$ Keun Hwa Chae, ${ }^{3}$ Amit Kumar, ${ }^{1 *}$ Yoon-Kyoung Cho,${ }^{2 *}$ In Su Lee ${ }^{1 *}$

${ }^{1}$ Creative Research Initiative Center for Nanospace-confined Chemical Reactions (NCCR) and Department of Chemistry, Pohang University of Science and Technology (POSTECH), Pohang 37673 (South Korea)

${ }^{2}$ Center for Soft and Living Matter, Institute for Basic Science (IBS) and Department of Biomedical Engineering, School of Life Sciences, Department of Chemical Engineering, School of Energy and Chemical Engineering Ulsan National Institute of Science and Technology (UNIST), Ulsan, 44919 (South Korea)

${ }^{3}$ Advanced Analysis Center, Korea Institute of Science and Technology, Seoul, 02792, (South Korea)

${ }^{4}$ Equally contributing first authors.

*Correspondence: insulee97@postech.ac.kr (I. S. L.); ykcho@ unist.ac.kr (Y.-K.C.); amitkumar@postech.ac.kr (A. K.) 


\section{Supplementary Movies}

Movie S1: (.avi format). Nanoparticle tracking analysis of MTex-500 with addition of $\mathrm{H}_{2} \mathrm{O}_{2}$. (Fig. 2f)

Movie S2: (.avi format). Nanoparticle tracking analysis of MTex-500 without addition of $\mathrm{H}_{2} \mathrm{O}_{2}$. (Fig. $2 \mathrm{~g}$ )

Movie S3: (.avi format). Removal of biofilm E.coli. using MTex-500. (Fig. 4)

Movie S4: (.avi format). Removal of S.aureus biofilm using MTex-500. (Fig. 4)

Movie S5: (.avi format). Application of MTex-500 for biofilm unclogging of spiral microchannel (Fig. and $\mathrm{S} 29, \mathrm{~S} 30)$.

Movie S6: (.avi format). Application of MTex-500 for biofilm unclogging from joint microchannel (Fig. and S29, S30). 


\section{S1. GENERAL INFORMATION}

\section{S1.1 Instruments and Characterization}

Transmission electron microscopy (TEM) was conducted using JEOL (JEM-2100), JEM-ARM200F [coupled with a scanning transmission electron microscope (STEM)-energy dispersive spectrometry (EDS) elemental mapping module], and JEM-2100F (coupled with an STEM-EDS elemental mapping and line profiling module) instruments. Scanning electron microscopy (SEM) imaging was performed using an XL30S FEG (Philips) instrument. XPS measurements were performed on a PHI versaprobe system, using a monochromatic $\mathrm{Al} \mathrm{K} \alpha$ source. High-resolution narrow scans were performed at constant pass energy of $58.7 \mathrm{eV}$ and steps of $0.1 \mathrm{eV}$. The data were converted to VAMAS format and processed using Avantage software. The binding energy (BE) scale was internally referenced to the $\mathrm{C} 1 \mathrm{~s}$ peak $(\mathrm{BE}$ for $\mathrm{C}-\mathrm{C}=284.8$ $\mathrm{eV})$. The contents of the metal elements in the nanoparticles were measured by inductive coupled plasma atomic emission spectrometry (ICP-AES) using Direct Reading Echelle ICP (LEEMAN). UV-vis spectroscopy was carried out with a JASCO V-650 UV-vis spectrophotometer. X- ray absorption spectroscopy (XAS) measurements for matrials were performed at 10D XAS KIST beamline in PLS, operating at $3.0 \mathrm{GeV}$ energy with a maximum storage current of $400 \mathrm{~mA}$. Magnetic properties of nanoparticles were measured using superconducting quantum interference device (SQUID) magnetometer (Quantum Design, MPMS XL-7), which is equipped with a 7 T superconducting magnet. X-ray diffraction patterns were obtained by using X-ray diffractometer (18 kW, Rigaku, Japan).

\section{S1.2 Reagents and Materials}

All chemicals were used without purification as commercially available unless otherwise noted. Commercially available compounds were used: All chemical reagents, unless otherwise stated were purchased from Sigma and used without further purification but degassed before use: $\mathrm{FeCl}_{3} \cdot 6 \mathrm{H}_{2} \mathrm{O}$ (Sigmaaldrich), $\mathrm{NaOH}$ (Samchun Chem.), Tannic acid (Sigma-Aldrich), $\mathrm{Co}\left(\mathrm{NO}_{3}\right)_{2} \cdot 6 \mathrm{H}_{2} \mathrm{O}$ (Sigma-aldrich), $\mathrm{H}_{2} \mathrm{O}_{2}$ (Samchun Chem.), Tetramethylbenzidine (Sigma-aldrich), Terephthalic acid (Sigma-aldrich), Dimethyl sulfoxide $>99.9 \%$ (Sigma-aldrich) was used as purchased without any purification.

\section{S2. EXPERIMENTAL PROCEDURES}

Synthetic procedure for MTex. To a mixture of graphene oxide $(1 \mathrm{mg} / \mathrm{ml})$ and $\mathrm{FeCl}_{3} .3 \mathrm{H}_{2} \mathrm{O}(100 \mu 1,10$ $\mathrm{mM}$ ) was added tannic acid $(100 \mu 1,10 \mathrm{mM})$ at $\mathrm{pH} 10$ (adjusted by $1 \mathrm{M} \mathrm{NaOH}$ ) and the reaction mixture 
was vortexed vigorously for $30 \mathrm{~s}$ at $25^{\circ} \mathrm{C}$, then reaction mixture was placed on shaker for $30 \mathrm{~min}$ at $80{ }^{\circ} \mathrm{C}$ then the resulting particles were collected by centrifugation and washed with DI water ( $1 \mathrm{ml}, 2$ times). In the next step, TA-GO-FeOOH nanocomposite from the previous step were dispersed in aqueous solution of $\mathrm{Co}\left(\mathrm{NO}_{3}\right)_{2}(2 \mathrm{ml}, 20 \mathrm{mM})$ and the reaction mixture was stirred for $2 \mathrm{~h}$ at $25^{\circ} \mathrm{C}$ leading to $\mathrm{Co}$ (II)-TA-GOFeOOH composite which was washed with DI ( $1 \mathrm{ml}, 2$ times) and freeze dried to lyophilize the sample. the lyophilized $\mathrm{Co}(\mathrm{II})-\mathrm{TA}-\mathrm{GO}-\mathrm{FeOOH}$ powder was transferred to an ceramic crucibleand placed in a box-type furnace, which was gradually heated with a rate of $5^{\circ} \mathrm{C} / \mathrm{min}$ to $500{ }^{\circ} \mathrm{C}$ for $5 \mathrm{~h}$ under atmosphere environment leading to MTex-500 having textured surface with small dendritic branches while maintaining the overall size and spheroidal nanorod morphology. Further to investigate thermal NC-transformation behavior, $\mathrm{Co}(\mathrm{II})-\mathrm{TA}-\mathrm{GO}-\mathrm{FeOOH}$ was also annealed under oxidative conditions at varying annealing temperatures $\left(T_{\mathrm{a}}\right.$ $\left.=600,700^{\circ} \mathrm{C}\right)$.

\section{S2.1. Synthetic procedure for control experiments.}

Synthesis with presynthesized $\boldsymbol{\beta}$-FeOOH : In a mixture of pre-synthesized $\beta$-FeOOH $\mathrm{NCs}^{1}$ (5 mg) and graphene oxide $(1 \mathrm{mg} / \mathrm{ml})$ tannic acid $(100 \mu \mathrm{l}, 10 \mathrm{mM})$ was added dropwise at pH 10 (adjusted by $1 \mathrm{M}$ $\mathrm{NaOH}$ ) and the reaction mixture was vortexed vigorously for $30 \mathrm{~s}$ at $25^{\circ} \mathrm{C}$, then reaction mixture was stirred for $30 \mathrm{~min}$ at $25{ }^{\circ} \mathrm{C}$ and resulting particles were collected by centrifugation and washed with DI water $(1 \mathrm{ml}, 2$ times). In the next step, the collected nanocomposite from the previous step were dispersed in aqueous solution of $\mathrm{Co}\left(\mathrm{NO}_{3}\right)_{2}(5 \mathrm{ml}, 20 \mathrm{mM})$ and the reaction mixture was stirred for $2 \mathrm{~h}$ at $25^{\circ} \mathrm{C}$ leading to nanocomposite which was washed with DI (1 ml, 2 times) and freeze dried to lyophilize the sample. The lyophilized sample was subjected to air annealing conditions at $500{ }^{\circ} \mathrm{C}$ for $5 \mathrm{~h}$ as described in above procedure.

Synthesis without GO template: In a solution of pre-synthesized $\beta$-FeOOH NCs ${ }^{1}(5 \mathrm{mg} / \mathrm{ml})$ tannic acid $(100 \mu 1,10 \mathrm{mM}$ ) was added dropwise at $\mathrm{pH} 10$ (adjusted by $1 \mathrm{M} \mathrm{NaOH}$ ) and the reaction mixture was vortexed vigorously for $30 \mathrm{~s}$ at $25{ }^{\circ} \mathrm{C}$, then reaction mixture was stirred for $30 \mathrm{~min}$ at $25{ }^{\circ} \mathrm{C}$ and resulting particles were collected by centrifugation and washed with DI water ( $1 \mathrm{ml}, 2$ times). In the next step, the collected nanocomposite from the previous step were dispersed in aqueous solution of $\mathrm{Co}\left(\mathrm{NO}_{3}\right)_{2}(1 \mathrm{ml}, 20$ $\mathrm{mM}$ ) and the reaction mixture was stirred for $2 \mathrm{~h}$ at $25{ }^{\circ} \mathrm{C}$ leading to nanocomposite which was washed with DI ( $1 \mathrm{ml}, 2$ times) and freeze dried to lyophilize the sample. The lyophilized sample was subjected to air annealing conditions at $500{ }^{\circ} \mathrm{C}$ for $5 \mathrm{~h}$ as described in above procedure.

Synthesis at 3D surface: To a mixture of polystyrene nanospehere $(1 \mathrm{mg} / \mathrm{ml})$ and $\mathrm{FeCl}_{3} .3 \mathrm{H}_{2} \mathrm{O}(10 \mu 1,10$ $\mathrm{mM}$ ) was added tannic acid $(10 \mu 1,10 \mathrm{mM})$ at $\mathrm{pH} 10$ (adjusted by $1 \mathrm{M} \mathrm{NaOH}$ ) and the reaction mixture 
was vortexed vigorously for $30 \mathrm{~s}$ at $25^{\circ} \mathrm{C}$, then reaction mixture was placed on shaker for $30 \mathrm{~min}$ at $80{ }^{\circ} \mathrm{C}$ then the resulting particles were collected by centrifugation and washed with deionised (DI) water (1 ml, 2 times). In the next step, the nanocomposite from the previous step were dispersed in aqueous solution of $\mathrm{Co}\left(\mathrm{NO}_{3}\right)_{2}(1 \mathrm{ml}, 20 \mathrm{mM})$ and the reaction mixture was stirred for $2 \mathrm{~h}$ at $25^{\circ} \mathrm{C}$ leading to $\mathrm{Co}(\mathrm{II})-\mathrm{TA}-\mathrm{FeOOH}$ composite which was washed with DI ( $1 \mathrm{ml}, 2$ times $)$ and freeze dried to lyophilize the sample.

FTIR and RAMAN Analysis of MTex-500: we acquired FTIR spectroscopy data to get more insight into the structure of MTex-500 (Figure S12). The stretching and bending vibration bands were observed in the range of $430 \pm 5 \mathrm{~cm}^{-1}$ and $520 \pm 5 \mathrm{~cm}^{-1}$. The difference in frequencies might be due to change in the bond lengths between $\mathrm{Fe} / \mathrm{Co}$ ions and $\mathrm{O}^{2-}$, which are located at octahedral and tetrahedral sites. Additionally, the coordination environment of cobalt ions in MTex-500 was also investigated by Raman spectroscopy (Figure S13). We identified five typical Raman bands at 198, $480,524,613$, and $687 \mathrm{~cm}^{-1}$. The band at 198 is attributed to the characteristics of tetrahedral sites $\left(\mathrm{CoO}_{4}\right)$, corresponding to ${ }^{1} \mathrm{~F}_{2} \mathrm{~g}$ symmetry, while the band at 480 and 524 are associated with $\mathrm{E}_{\mathrm{g}}$ and $\mathrm{F}_{2} \mathrm{~g}^{2}$ symmetry, respectively. A weak band at $613 \mathrm{~cm}^{-1}$ is related to $\mathrm{F}_{2} \mathrm{~g}^{2}$ symmetry. The strong band at $687 \mathrm{~cm}^{-1}$ is attributed to the characteristics of octahedral sites $\left(\mathrm{CoO}_{6}\right)$, matching well with the $\mathrm{A}^{1} \mathrm{~g}$ species in the $\mathrm{Oh}$ spectroscopic symmetry. In comparison to $\mathrm{Co}_{3} \mathrm{O}_{4}$ and $\mathrm{CoO}$, the $\mathrm{Raman}$ peaks at 687 and $680 \mathrm{~cm}^{-1}$ respectively is blue-shifted to $679 \mathrm{~cm}^{-1}$ in MTex-500, and peak intensity is decreased in comparison with $\mathrm{Co}_{3} \mathrm{O}_{4}$. The changes in Raman symmetry in MTex-500 suggest that the original coordinative environment of octahedral sites is changed, due to the change in cation-anion bond lengths.

S2.2. Procedure for testing cataltyic properties of MTex towards ROS-production. The mother solution of 3,3',5,5'-tetramethylbenzidine (TMB) was prepared in DMSO, protected from light and used the day it was prepared. Stock solutions of Hepes buffer $0.1 \mathrm{M}, \mathrm{pH} 7.4$ or sodium acetate buffer $0.2 \mathrm{M}$, pH 3.5, were prepared using milliQ $\mathrm{H}_{2} \mathrm{O}$. To carry out the kinetic UV-visible measurements to a solution of TMB and $\mathrm{H}_{2} \mathrm{O}_{2}$ in buffer (Hepes buffer $0.1 \mathrm{M}, \mathrm{pH} 7.4$ or sodium acetate buffer $0.2 \mathrm{M}, \mathrm{pH} 3.5$ ) was added $5 \mu \mathrm{l}$ of MTex-500 (1 mg/ml, suspension in water). The absorbance of oxidized TMB was immediately monitored at $652 \mathrm{~nm}$ for $16 \mathrm{~min}$. Final volume in the cuvette was $1 \mathrm{ml}$. Final concentrations were $[\mathrm{TMB}]=816 \mu \mathrm{M}$, $\left[\mathrm{H}_{2} \mathrm{O}_{2}\right]=500 \mathrm{mM}$. Control experiments were performed in the presence of MTex-700, sMTex, $\mathrm{Fe}_{3} \mathrm{O}_{4}$ or $\mathrm{Co}_{3} \mathrm{O}_{4}$ having the same amount of $\mathrm{Fe}$ and $\mathrm{Co}$, with the same $\mathrm{TMB} / \mathrm{H}_{2} \mathrm{O}_{2}$ mole ratios. Michaelis-Menten kinetic curve of MTex-500 was plotted from the respective initial velocities against $\mathrm{H}_{2} \mathrm{O}_{2}$ concentrations. The maximum velocity $\left(\mathrm{V}_{\max }\right)$ was calculated via the Lineweaver-Burk plotting (Fig. S13). 


\section{Detection of Hydroxyl Radical $(\bullet \mathrm{OH})$}

The generation of ${ }^{\circ} \mathrm{OH}$ was investigated by using terephthalate (TA) to form 2-hydroxyl terephthalate as a fluorescence indicator. ${ }^{2}$ Four experimental groups including TA $(5 \mathrm{mM}), \mathrm{H}_{2} \mathrm{O}_{2}(10 \mathrm{mM})+$ TA, MTex-500 $(5 \mu \mathrm{g} / \mathrm{ml})+\mathrm{TA}+\mathrm{H}_{2} \mathrm{O}_{2}(\mathrm{D})$, were evaluated. The reaction was moitored at room temperature for $15 \mathrm{~min}$ and the mixtures were withdrawn and their fluorescence was detected using $312 \mathrm{~nm}$ as excitation wavelength which gave the fluorescence of emission at wavelength of $425 \mathrm{~nm}$ which is related with $\bullet \mathrm{OH}$ production.

S2.3. Nanotracking analysis (NTA): In a typical procedure varying concentration of hydrogen peroxide (30\% conc) was added to $1 \mathrm{mg} / \mathrm{ml}$ solution of MTex-500 and diluted to the concentration regime suitable for NTA measurement $\left(10 \mu \mathrm{l}\right.$ in $2 \mathrm{ml}$ of MilliQ water $-2.2 \times 10^{8}$ particles/ml). Nanoparticle Tracking Analysis (NTA 3.1) from NanosightNS300 was used to record the movement of the motors for 30 seconds ( 25 frames per second) at room temperatures and a total number of 5243 particles in 749 frames. The StokesEinstein equation was used to correlate the tracking coordinates obtained from the movement of the particles with their size. By analyzing the video, $\mathrm{x}, \mathrm{y}$ coordinates / positions of each particle were determined as a function of time intervals. Upon $0.5 \mathrm{v} / \mathrm{v} \%$ to $3 \%$ hydrogen peroxide addition rotational movement was observed and movement was found to be proportional to the added amount of hydrogen peroxide. Average MSD of the MTex-500 in different media after the addition of $2 \% \mathrm{H}_{2} \mathrm{O}_{2}$, was calculated from the tracking coordinates of 100 particles. The fitting of the MSD allows for calculation of the velocity of the nanomotors by using the model proposed by Golestanian and co-workers ${ }^{3}$. While a purely diffusive system would show only a linear component according to the equation (4D) $\Delta \mathrm{t}$, MSD curves for MTex-500 are not linear and show a parabolic fit according to the equation (4D) $\Delta t+\left(v^{2}\right)\left(\Delta t^{2}\right)$, from which we extracted the velocity of the particles.

The statistical distribution plot of the individual MSD for each tracked nanoparticle with and without fuel in DI as well as in PBS, cell media are presented in Figure S, while the average MSD plot are shown in Figure 3h. The velocity of the MTex-500 with $2 \% \mathrm{H}_{2} \mathrm{O}_{2}$ was around $41 \mu \mathrm{m} / \mathrm{s}$ in DI while in PBS and cell media decreased velocities and MSDs were observed compared to DI. Brownian motion and a typical linear MSD curve was observed when studying the movement of MTex-500 without hydrogen peroxide fuel.

\section{Bacterial culture and biofilm formation}

The bacterial cell, E. coli MG1655, E. coli ATCC 25922 and S. aureus ATCC 25923, was streaked on the Luria-Bertani (LB) agar plate (Difco Generic LABWARE,) from their stocks and incubated at $37^{\circ} \mathrm{C}$ with $5 \% \mathrm{CO}_{2}$ for $18 \mathrm{~h}$. For the growth of E. coli MG1655, was plated on the LB agar plate containing $100 \mu \mathrm{g} / \mathrm{mL}$ 
ampicillin. The isolated colony of bacteria was inoculated in the $10 \mathrm{ml}$ of liquid LB medium (Difco Generic LABWARE) and incubated at $37^{\circ} \mathrm{C}$ with $150 \mathrm{rpm}$ for $10 \mathrm{~h}$ till it reaches to the logrithm phase. For the biofilm formation, about $2 \times 10^{6} \mathrm{CFU} / \mathrm{mL}$ of actively growing bacterial cells were inoculated in the round bottom flat polystyrene dishes (TPP Culture Plate Switzerland) containing the LB broth. The plate was incubated statically at $37{ }^{\circ} \mathrm{C}$ with $5 \% \mathrm{CO}_{2}$ for $24 \mathrm{~h}$. Biofilms were encountered with the MTex-500 or control nanoparticles to check the antibacterial and EPS matrix degradation efficacy.

Antibacterial action of MTex. Antibacterial effect of MTex-500 were determined via the number of colony-forming units (CFU) using the culturing method. Briefly, the bacterial cell E. coli ATCC 25922 and S. aureus ATCC 25923, was streaked on the Luria-Bertani (LB) agar plate (Difco Generic LABWARE,) from their stocks and incubated at $37{ }^{\circ} \mathrm{C}$ with $5 \% \mathrm{CO}_{2}$ for $18 \mathrm{~h}$. The isolated colony of bacteria was inoculated in the $10 \mathrm{~mL}$ of liquid LB medium (Difco Generic LABWARE) and incubated at $37^{\circ} \mathrm{C}$ with 150 rpm for $10 \mathrm{~h}$ till it reaches to the logarithm phase. Four groups of bacteria were tested: (i) bacteria; (ii) bacteria $+\mathrm{H}_{2} \mathrm{O}_{2}(1 \%)$; (iii) bacteria $+\mathrm{Fe}_{3} \mathrm{O}_{4}(500 \mu \mathrm{g} / \mathrm{ml})+\mathrm{H}_{2} \mathrm{O}_{2}$ (1\%); (iv) (ii) bacteria + MTex (500 $\left.\mu \mathrm{g} / \mathrm{ml}\right)$. The final concentration of bacteria was $1.0 \times 10^{8}-1.0 \times 10^{9} \mathrm{CFU} / \mathrm{mL}$. After incubation, to determine the efficacy of MTex-500 for CFU, aliquots were taken from the tube containing the bacteria/nanoparticle suspensions and serially diluted $10^{1}-10^{3}$-fold in sterile PBS and then streaked on LB agar plates for $18 \mathrm{~h}$ and number of colony forming units (CFUs) was counted. All of the experiments and controls were performed in triplicate.

Invitro biofilm model on polystyrene dishes. Biofilms were formed on round bottom flat polystyrene dishes (TPP Culture Plate Switzerland). Two separate sHA dishes were inoculated with $\sim 2 \times 10^{6} \mathrm{CFU}$ of E. coli ATCC 25922 and S. aureus ATCC 25923 per $\mathrm{mL}$ in LB broth. The plate was incubated statically at $37^{\circ} \mathrm{C}$ with $5 \% \mathrm{CO}_{2}$ for $24 \mathrm{~h}$. The biofilms were collected and analyzed for MTex-500 binding and catalytic activity.

CFU determination: For the CFU determination from the treated sample, media was removed from the wells and washed with the $200 \mu \mathrm{l}$ of PBS. Then water bath sonication was used for the homogenization maintaining the condition 30-s pulse with 7W output (Branson Sonifier 150; Branson Ultrasonics, CT, USA). After that it was serially diluted to $10 \mathrm{X}, 100 \mathrm{X}$ and 1000X in the PBS. $100 \mu 1$ bacterial solution from each dilution was plated on the LB agar plates and incubated at $37{ }^{\circ} \mathrm{C}$ with $5 \% \mathrm{CO}_{2}$ for $18 \mathrm{~h}$ to estimate the CFU number. PBS was used for the control instead of nanoparticles. Triplicate assay was performed to count the CFU number. 


$$
c f u / m l=\frac{\text { no.s of colonies } \times \text { dilution factor }}{\text { volume of inoculum used for plating }}
$$

\section{Calculations of Log Reduction and Pecent Reduction:}

$\log$ Reduction $=\log _{10}\left(\frac{\mathrm{A}}{\mathrm{B}}\right)$

Where $\mathrm{A}=$ Number of viable bacteria before treatment $\left(\mathrm{CFU} \mathrm{mL} \mathrm{m}^{-1}\right)$, and $\mathrm{B}=$ Number of viable bacteria after treatment $\left(\mathrm{CFU} \mathrm{mL} \mathrm{m}^{-1}\right)$.

Calculation of Percentage Reduction

Percent Reduction $=\frac{(\mathrm{A}-\mathrm{B}) \times 100}{\mathrm{~A}}$

Where $\mathrm{A}=$ Number of viable bacteria before treatment $\left(\mathrm{CFU} \mathrm{mL} \mathrm{m}^{-1}\right)$, and $\mathrm{B}=$ Number of viable bacteria after treatment $\left(\mathrm{CFU} \mathrm{mL} \mathrm{m}^{-1}\right)$.

\section{Crystal violet staining}

The biofilm plates after treatment were washed gently by PBS for three times. The plates were stained with $1 \mathrm{~mL}$ of $0.2 \%$ crystal violet for $30 \mathrm{~min}$ at room temperature. Extra stain was washed with PBS and $0.5 \mathrm{~mL}$ $95 \%$ ethanol was added to each well for quantification. The corresponding absorbance was measured at 590 $\mathrm{nm}$ using plate reader (TECAN, Morrisville, NC, USA).

\section{Fluorescence imaging (Live-Dead bacterial assay)}

The bacterial viability before and after treatment with MTex-500 was determined by live-dead bacterial staining assay (Molecular Probes, Carlsbad, CA, USA)). $3 \mu 1$ mixture of SYTO 9 (485/498 nm) and propidium iodide $(535 / 617 \mathrm{~nm})$ was added in about $1 \mathrm{ml}$ of bacterial biofilm. It was incubated at dark in room temperature for $30 \mathrm{~min}$ and imaged by confocal microscopy (Flash 4.0; Hamamatsu, Japan) using NIS-Elements software (Nikon, Japan). Live bacteria were observed as green color due to SYTO 9 dye whereas dead one as red color due to propidium iodide dye. The 3D confocal fluorescence images are obtained by stacking 30 images, $\sim 100 \mu \mathrm{m}$ depth along the z-axis 
To compare the efficacy of MTex-500, the aforementioned study was carried out with $1 \% \mathrm{H}_{2} \mathrm{O}_{2}$ and Mtex$500(500 \mu \mathrm{g} / \mathrm{ml})$ as well. The fluorescence intensity (at $561 \mathrm{~nm})$ of each section $\left(200 \times 100 \times 1 \mu \mathrm{m}^{3}\right)$ is monitored. ${ }^{3}$

Penetration of MTex-500 into the biofilms. In order to visualize the penetration of MTex-500 in biofilm, the rhodamine B (RB) labeled MTex-500 NCs were used. Bioflms were exposed to RB-labled MTex-500 in PBS at PH 7.4 with or without the addition of $\mathrm{H}_{2} \mathrm{O}_{2}$ and control $\mathrm{Fe}_{3} \mathrm{O}_{4}$ particle. After incubated for 10 min, the excess NCs were removed and the biofilms were gently washed with PBS. Then the penetration and accumulation ability of nanoparticles were examined by determining the fluorescent intentsity of RB $\left(\lambda_{561}\right)$ over the different distance from the top (Z-axis direction). The confocal laser scanning microscopy $(\mathrm{CLSM})$ images the $3 \mathrm{D}$ section $\left(200 \times 100 \times 1 \mu \mathrm{m}^{3}\right)$ recorded using an sCMOS camera (Flash 4.0; Hamamatsu, Japan) and system was controlled using NIS-Elements software (Nikon, Japan).

\section{Morphology Characterization of Bacteria}

\section{SEM}

The morphology of bacteria before and after treatment with MTex-500 was characterized through SEM. Before and after treated bacteria was collected and washed in the PBS. It was fixed by adding $2.5 \%$ glutaraldehyde on the silicon for 1 hour. After $1 \mathrm{~h}$, it was rinsed with the PBS followed by series of dehydration step using $30 \%, 50 \%, 70 \%, 80 \%$ and $100 \%$ leaving the sample $10 \mathrm{~min}$ in each concentration. Then the sample was left for air dry and sputter coated with gold before proceeding the SEM.

\section{TEM}

Before and after treated bacteria was collected and washed in the PBS. $10 \mu \mathrm{L}$ of bacterial suspension was kept on the parafilm in the petridish. The copper grid was placed invertly above the bacterial suspension and excess bacterial solution was removed using blotting paper. A drop of $2 \%$ aqueous uranyl acetate was added on the specimen and left for one minute. Then the grid was left to dry removing the excess stain and placing on another plate. After drying, it was proceeded for the TEM.

ROS stress assay in bacteria treated with MTex-500. ROS-stress in the bacterial cells was determined by using dichlorodihydrofluorescein diacetate $\left(\mathrm{DCFH}_{2}-\mathrm{DA}\right)$ assay. E. coli ATCC 25922 and S. aureus ATCC 25923 were grown till the number become $1 \times 10^{6} \mathrm{CFU} \mathrm{mL}-1$ and they were treated with different 
concentration MTex $500\left(50 \mu \mathrm{g} \mathrm{mL}^{-1}, 100 \mu \mathrm{g} \mathrm{mL}^{-1}\right.$ and $\left.500 \mu \mathrm{g} \mathrm{mL}^{-1}\right)$ at $37^{\circ} \mathrm{C}$. Then, the cells were washed with the PBS and incubated with $100 \mu \mathrm{M}$ of $\mathrm{DCFH}_{2}$-DA for $45 \mathrm{~min}$ in the dark. The cells were washed and resuspended in the PBS followed by measuring the fluorescence intensity in spectrophotometer (TECAN, Morrisville, NC, USA) by excitation at $485 \mathrm{~nm}$ and emission at $535 \mathrm{~nm}$. As shown in Figure S27, fluorescence intensity increases with increase in NP concentration, indicating the higher rates of ROS production upon treatment with NPs.

Disruption of biofilm in microfluidic channels. First, Spiral and joint microfluidic channel were designed by using 3D CAD program and milled with a CNC micro milling machine (3D modeling machine; M \& I CNC Lab, Pyeongtaek, Korea). 2 mm Polycarbonate sheets (PC: I-Components Co., Ltd., Pyeongtaek, Korea) were used for the body. The milled chips were then vapor polished using dichloromethane and thermally bonded to a $0.125 \mathrm{~mm}$ polycarbonate film (3M, USA) at the bottom. These channels were connected to syringe pump (Pico plus elite, Harvard Apparatus). Biofilm of E. coli MG1665 (fluorescent tagged) was developed on this microchannel by inoculating with about $2 \times 10^{6} \mathrm{CFU} / \mathrm{ml}$ at $37^{\circ} \mathrm{C}$ with $5 \%$ $\mathrm{CO}_{2}$. For biofilm formation on the walls of the microchannels, we injected $100 \mu \mathrm{l}$ of the inoculated culture medium through the microfluidic channel and biofilms were cultured for $42 \mathrm{~h}$. Next, we injected the small volume (50 $\mu$ l for spiral, $5 \mu \mathrm{l}$ for joint channel) of MTex $(500 \mu \mathrm{g} / \mathrm{ml})$ mixed with $1 \% \mathrm{H}_{2} \mathrm{O}_{2}$ were injected inside the channel incubated for $10 \mathrm{~min}$, exposed to magnetic field. A permanent magnet was mounted to the arm of 3-axis micromanipulator (ZABER technologiesstages controllers), and microfluidic channels were attached to permanent place. In experiments, we moved the magnet along the microfludic axis using zaber console sofware to achieve a desired motion pattern with $45 \mu \mathrm{m}$ precision. Real-time images are recorded by using MiniLumi E, DNR Bio-Imaging Systems Ltd. with Trans-UV illumination. The data are representative of the three independent experiments. 


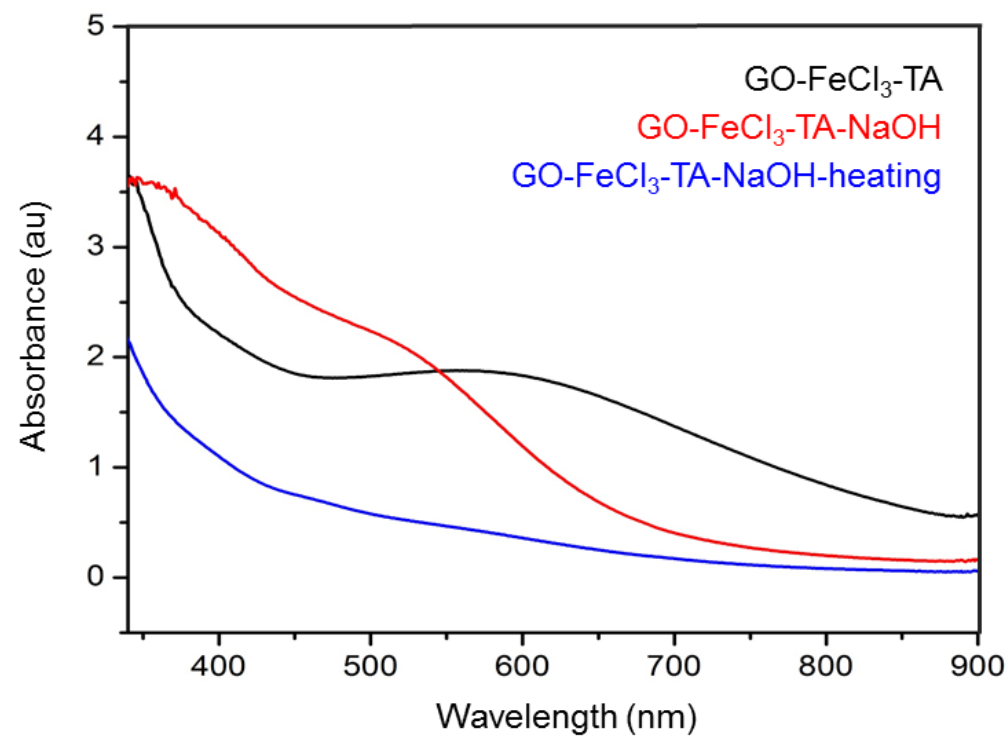

Figure S1. UV-vis spectroscopy data to monitor the in situ nanocrystallization of $\beta$-FeOOH from the mixture of GO, TA and $\mathrm{FeCl}_{3}$ : change in spectra of mixture of $\mathrm{GO}$, TA and $\mathrm{FeCl}_{3}$ before (black) and after (red) adding $\mathrm{NaOH}$ is due to TA-Fe(III) complexation under basic conditions. Further, heating the reaction mixture results decomplexation and crystallization of $\beta$-FeOOH, loosing characteristic charge-transfer broad absorption in visible region (blue). 

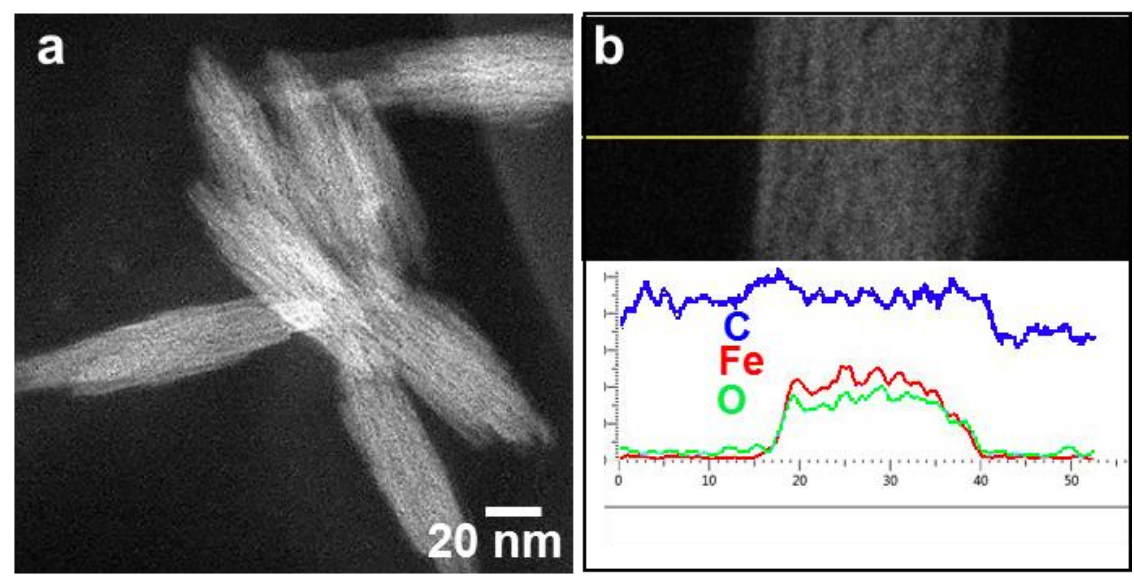

Figure S2. a, Dark Field STEM images of TA-GO-FeOOH, b, EDS line profile of TA-GO-FeOOH. Line profiling data shows the presence of thin polymeric (indicated by presence of carbon) film on $\beta-\mathrm{FeOOH}$ rod. 


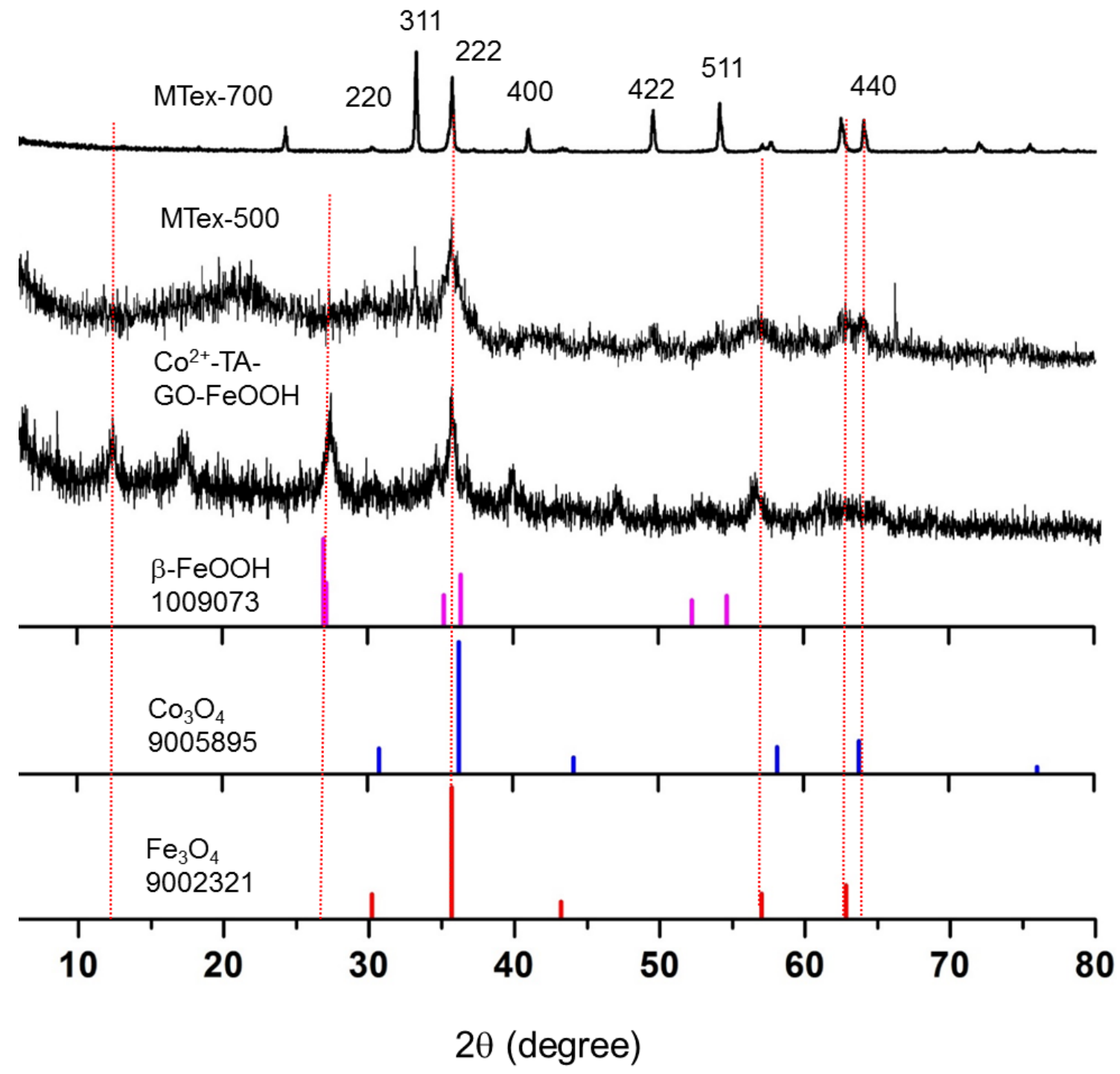

Figure S3. X-ray diffraction (XRD) patterns of Co(II)-TA-GO-FeOOH, MTex-500 and MTex-700. Broad XRD pattern of MTex-500 is due to the mixed metal oxide metaphasic semi-amorphous state of the nanocrystal; whereas, MTex-700 shows sharp characteristic XRD pattern due to crystalline phase. 

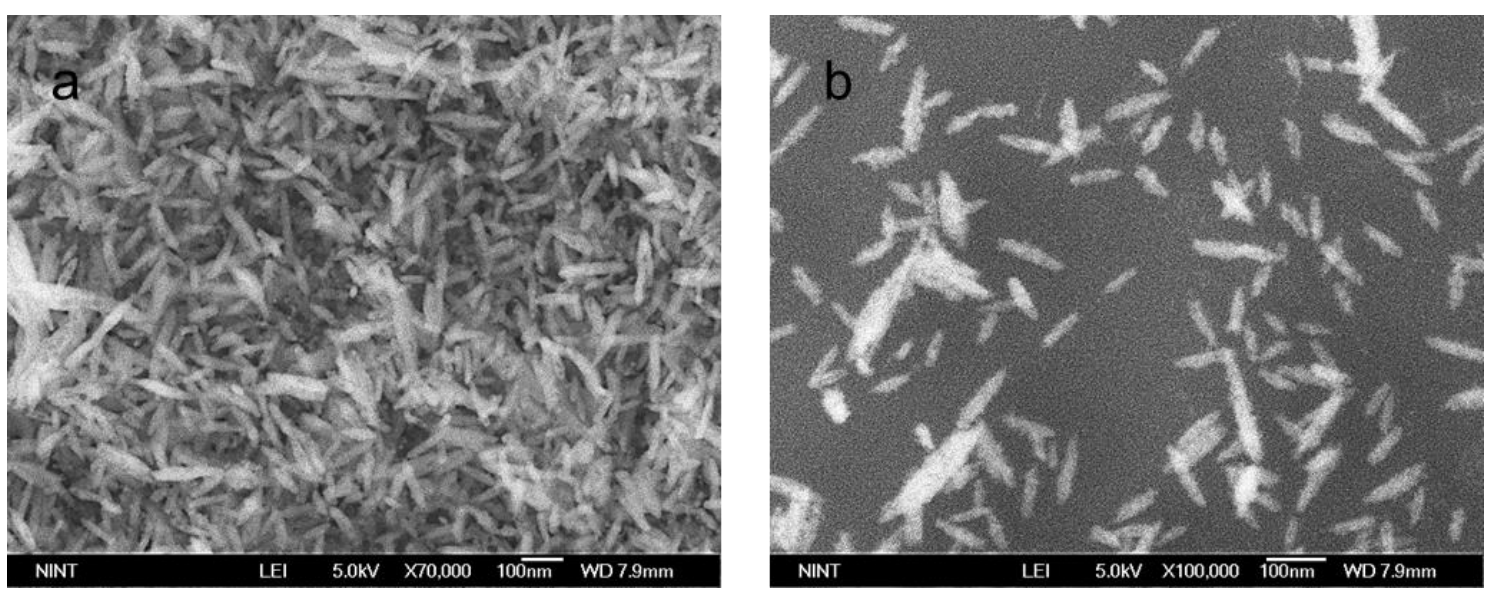

Figure S4. a, Low resolution, b, Higher magnification FE-SEM images of MTex-500. 


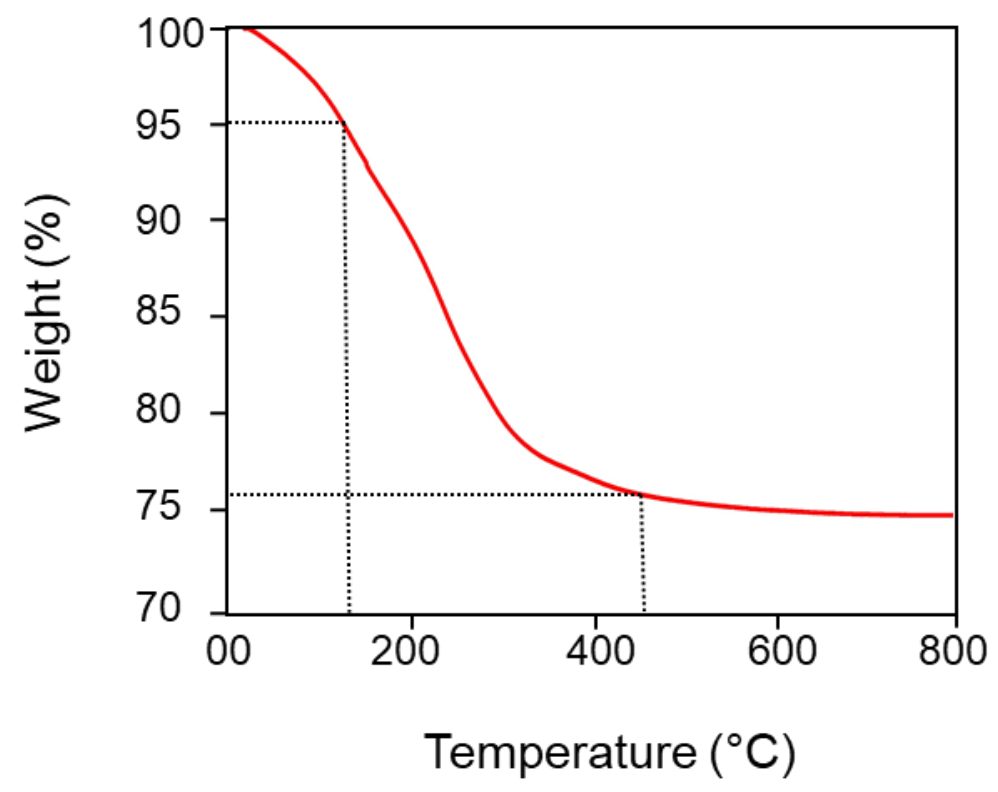

Figure S5. TGA analysis of $\mathrm{Co}(\mathrm{II})-\mathrm{TA}-\mathrm{GO}-\mathrm{FeOOH}$ nanocomposite, which depicts two endothermal processes- one up to $140{ }^{\circ} \mathrm{C}$, the weight loss of adsorbed water was observed. From $140{ }^{\circ} \mathrm{C}$ to $430{ }^{\circ} \mathrm{C}$, the weight loss derived from thermal dehydroxylation of $\beta-\mathrm{FeOOH}$ and from the thermal decomposition of GO and TA content. From these data, we can conclude that thermal transformation of $\beta$-FeOOH nanorods to MTex occurred from $140{ }^{\circ} \mathrm{C}$ to $430{ }^{\circ} \mathrm{C}$. 

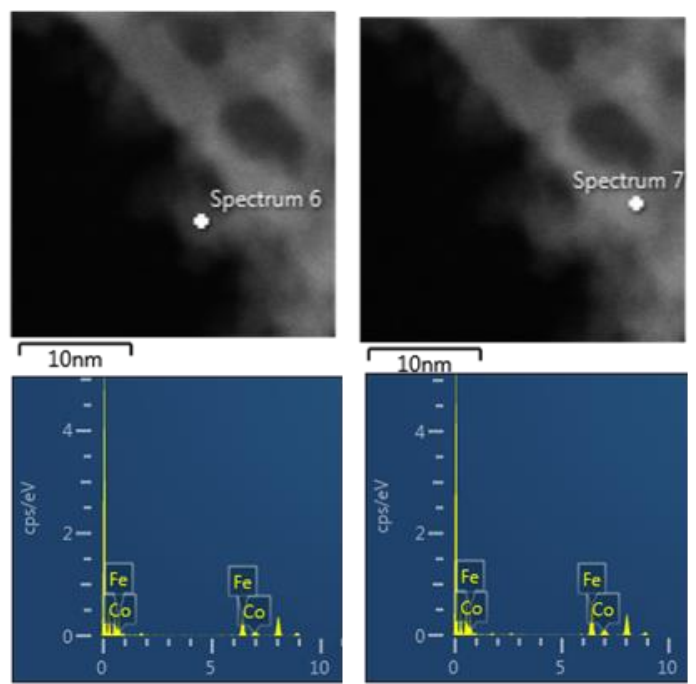

\begin{tabular}{|l|c|c|}
\hline $\begin{array}{c}\text { Elemen } \\
\mathrm{t}\end{array}$ & $\mathrm{Wt} \%$ & $\begin{array}{c}\text { Atomic } \\
\%\end{array}$ \\
\hline $\mathrm{Fe}$ & 88.66 & 84.19 \\
\hline Co & 11.75 & 10.81 \\
\hline Total: & 100.0 & 100.0 \\
\hline
\end{tabular}

\begin{tabular}{|l|c|c|}
\hline $\begin{array}{c}\text { Elemen } \\
\mathrm{t}\end{array}$ & $\mathrm{Wt} \%$ & $\begin{array}{c}\text { Atomic } \\
\%\end{array}$ \\
\hline $\mathrm{Fe}$ & 87.86 & 88.42 \\
\hline $\mathrm{Co}$ & 12.14 & 11.58 \\
\hline Total: & 100.0 & 100.0 \\
\hline
\end{tabular}

Figure S6. EDS point analysis of MTex-500 measured at different locations in the same nanostructure: $\mathrm{Fe} / \mathrm{Co}$ atomic ratios measured on the dendritic branches at outer surface (Spectrum 6) and on the backbone (Spectrum 7) are comparable, indicating significant intermetallic mixing during annealing process $\left(500{ }^{\circ} \mathrm{C}\right.$, $5 \mathrm{~h}$ ). 
Table S1: Contents of Fe and Co in MTex-500 and MTex-700 detected by ICP-OES

\begin{tabular}{lll}
\hline Sample & Fe (wt \%) & Co (wt \%) \\
\hline MTex-500 & 70.27 & 8.37 \\
MTex-700 & 60.43 & 6.88
\end{tabular}



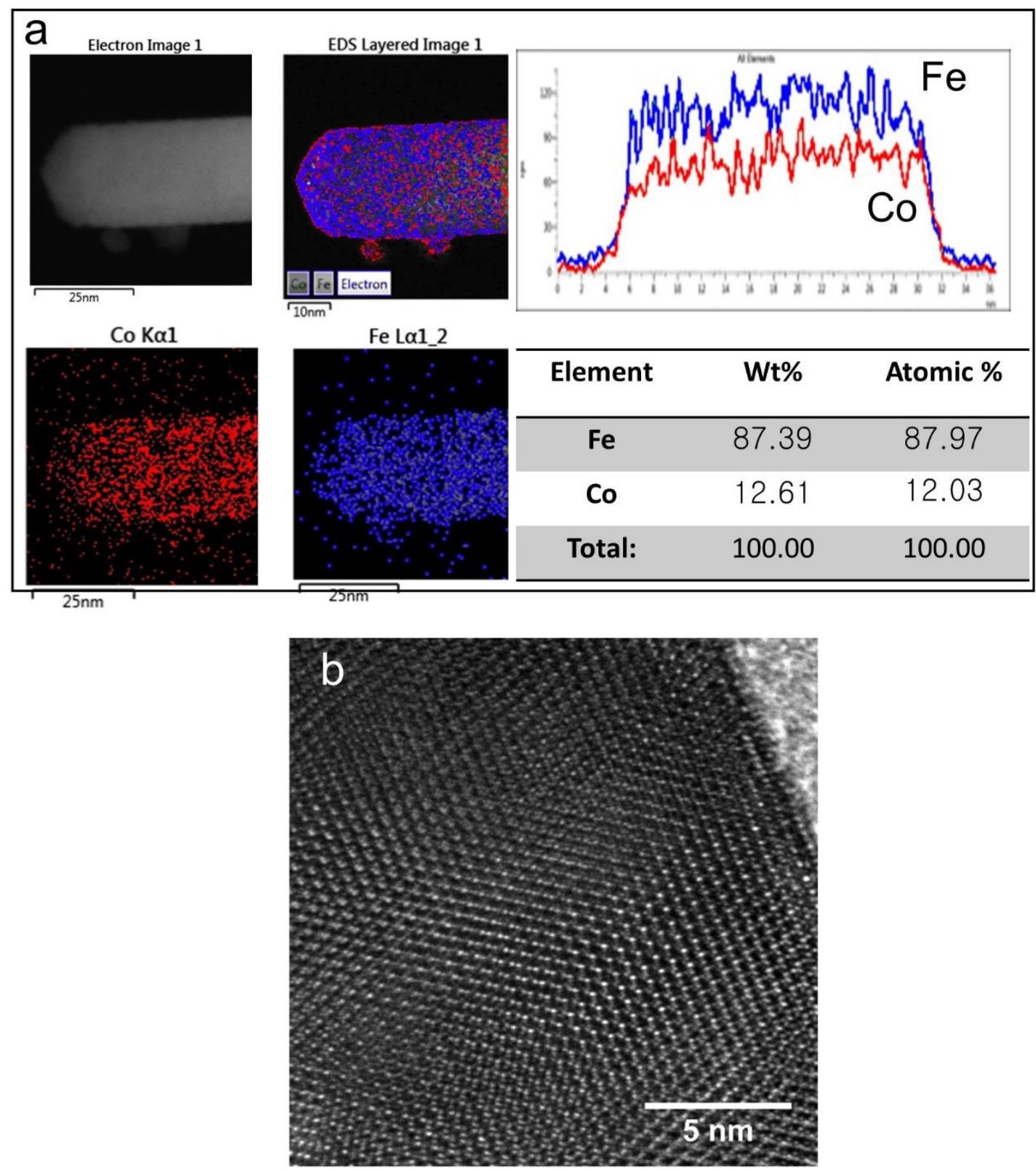

Figure S7. a, HAADF-STEM image, EDS elemental mapping and EDS line profiling of MTex-700. b, HRTEM of MTex-700. Homogenous spatial distribution of Co (red) and Fe (blue) elements indicate the intermetallic mixing. 

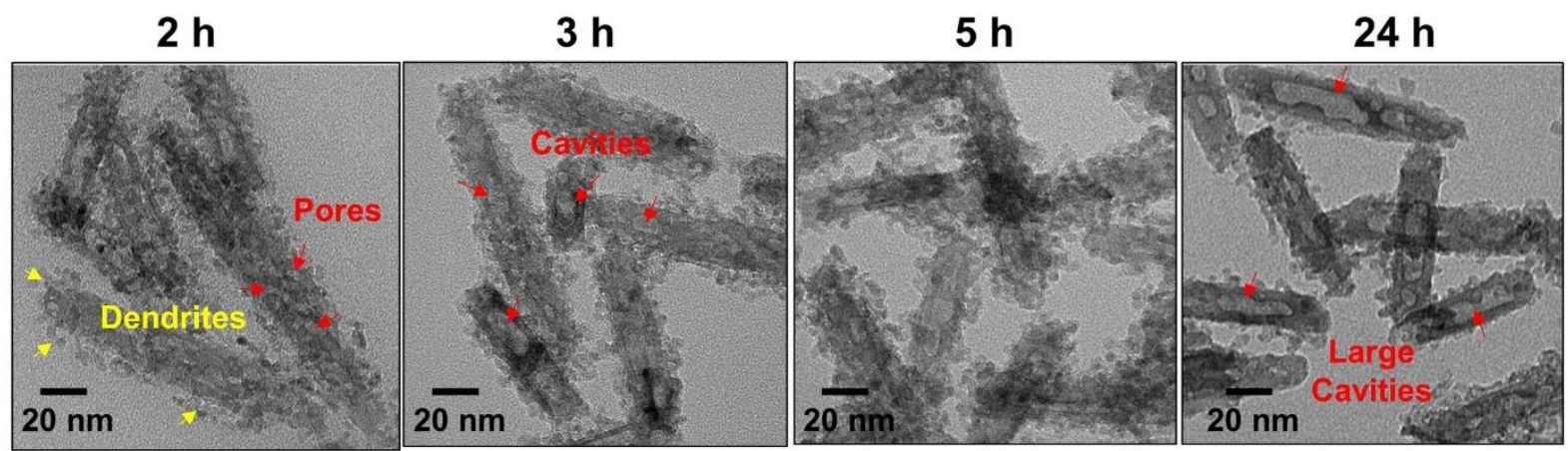

Figure S8. TEM images for time course analysis of air annealing of $\mathrm{Co}(\mathrm{II})-\mathrm{TA}-\mathrm{GO}-\mathrm{FeOOH}$ at $500{ }^{\circ} \mathrm{C}$ : emergence of thin dendritic branches (yellow arrows) and small pores (red arrows) within $2 \mathrm{~h}$, small pores merging to form cavities within $5 \mathrm{~h}$ (red arrows) and after $24 \mathrm{~h}$, formation of hollow tubular structures having single large cavities (red arrows). 

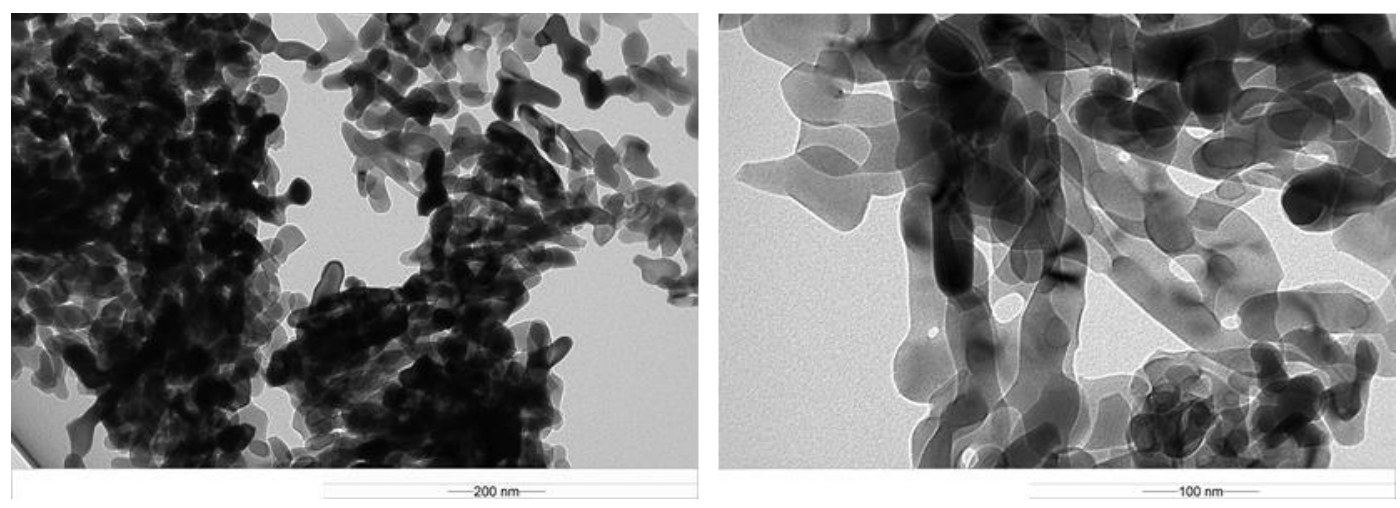

Figure S9. TEM images of air annealing of $\beta-\mathrm{FeOOH}$ mixed with $\mathrm{Co}\left(\mathrm{NO}_{3}\right)_{2}$ at $500{ }^{\circ} \mathrm{C}$. 

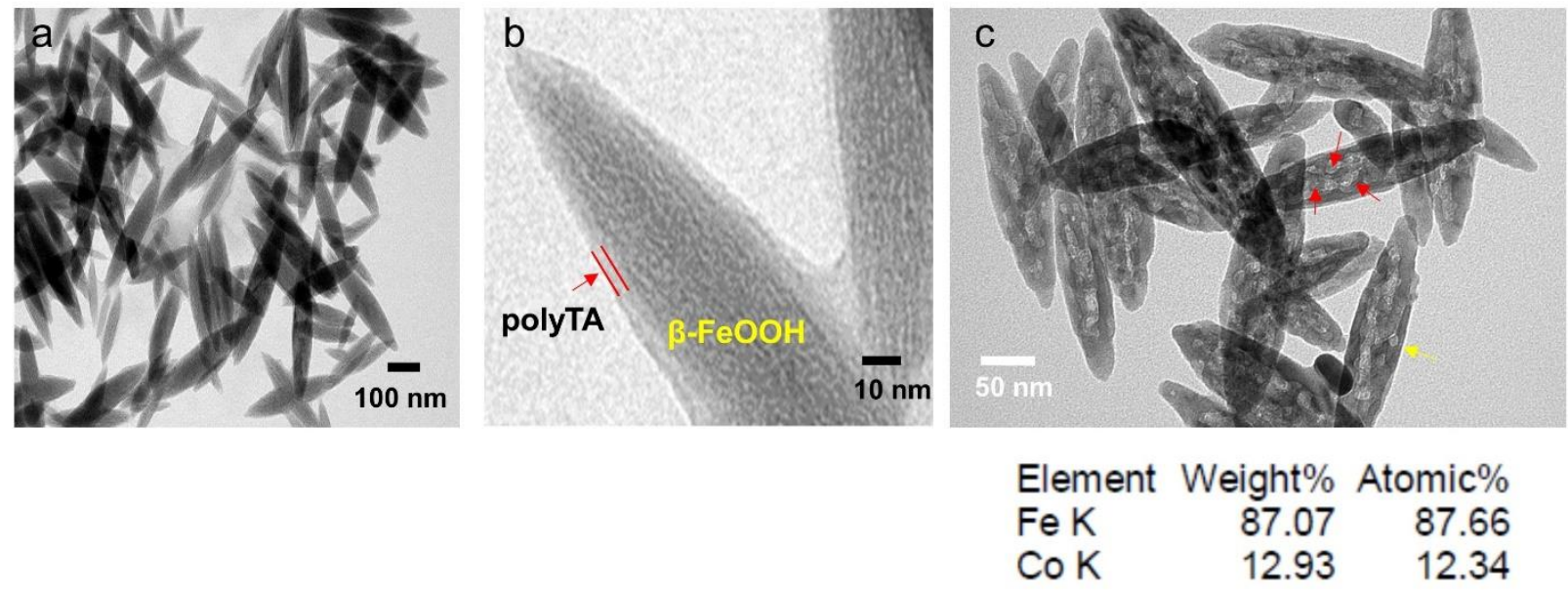

Figure S10. a, TEM image of $\beta$-FeOOH-TA-GO composite. b, High Resolution TEM image of $\beta$-FeOOHTA-GO composite, a lighter contrast polymeric coating on $\beta$-FeOOH NC can be easily visualized. c, TEM image of sMTex annealed at $500{ }^{\circ} \mathrm{C}$, showing only the presence of cavities (red arrows) without any dendritic texture on the surface (yellow arrow). 


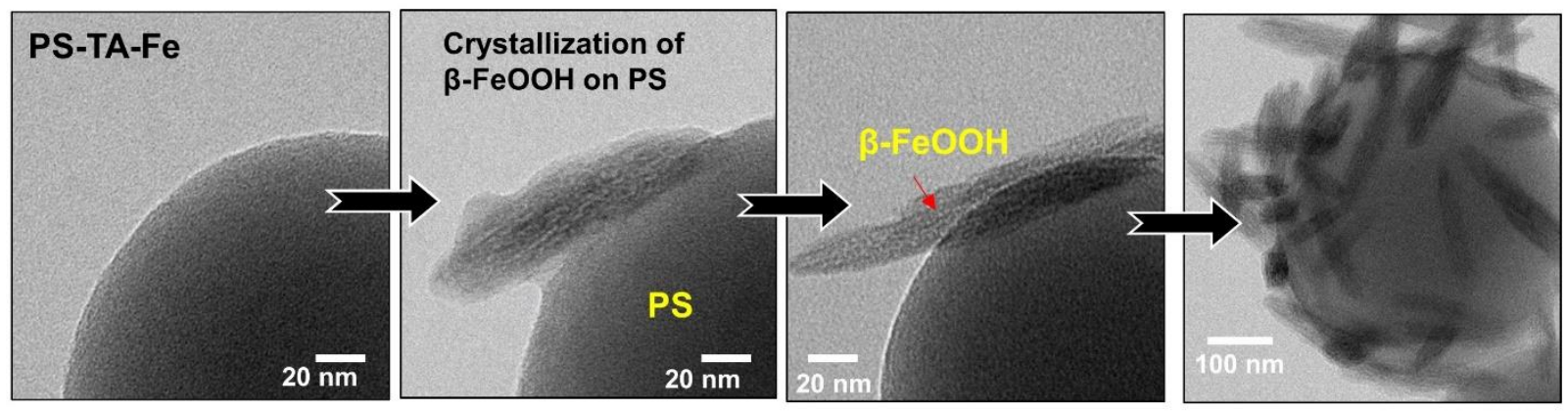

Figure S11. TEM images to study in situ nanocrystallization of $\beta-\mathrm{FeOOH}$ from the composite of polystyrene (PS) as $3 \mathrm{D}$ template, $\mathrm{TA}$ and $\mathrm{FeCl}_{3}$ : conversion of smooth coating of TA-Fe on PS, to $\beta-\mathrm{FeOOH}$ nanocrystal can be visualized at different times of the reaction. 


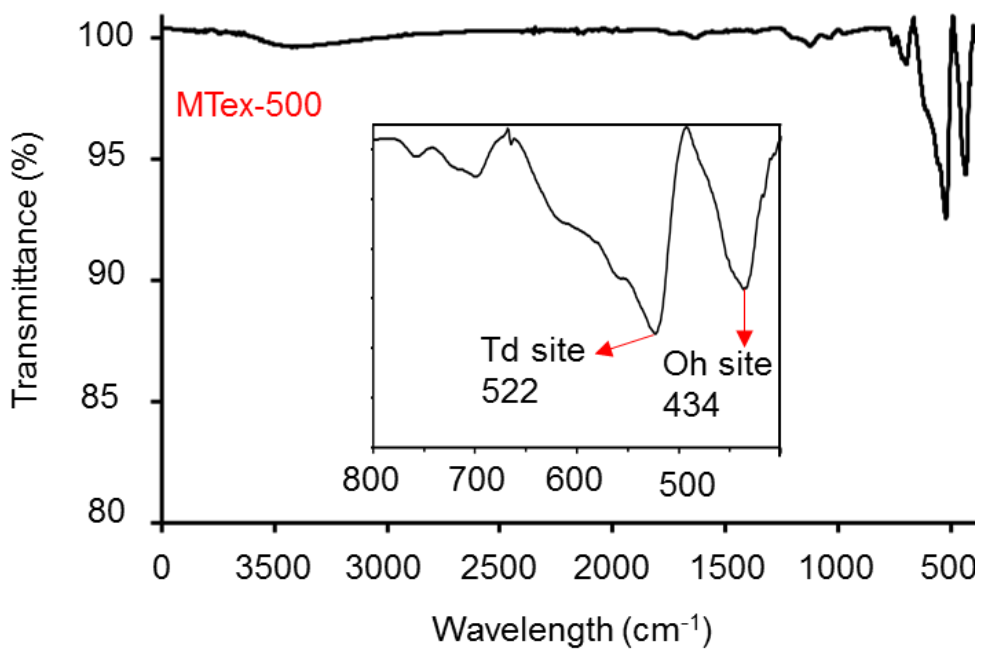

Figure S12: Fourier -transform infrared spectra of MTex-500. 


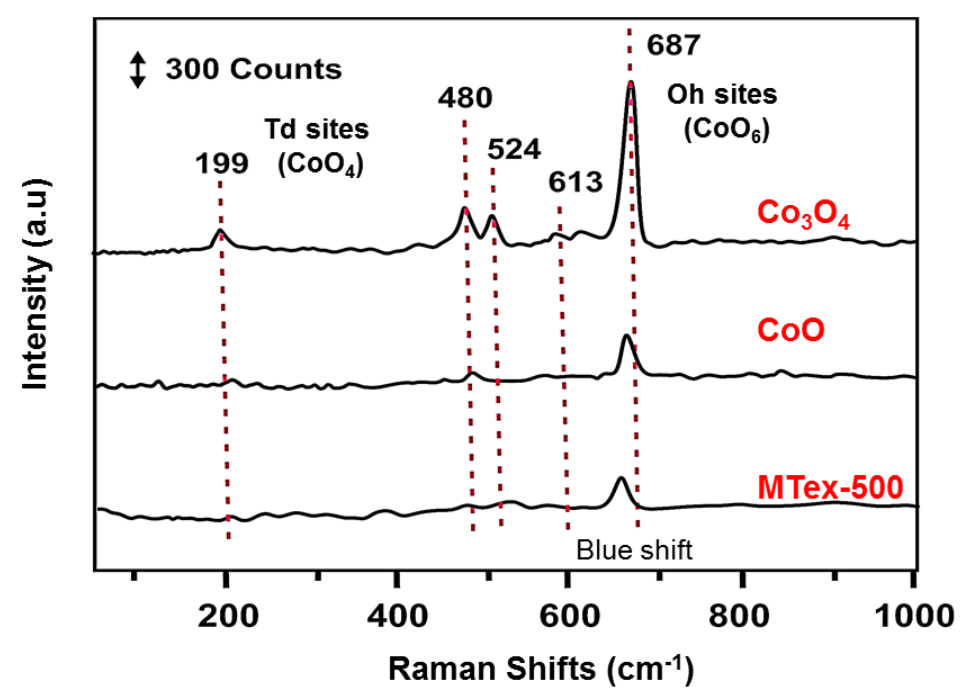

Figure S13: RAMAN spectra of $\mathrm{Co}_{3} \mathrm{O}_{4}, \mathrm{CoO}$ and MTex-500. 

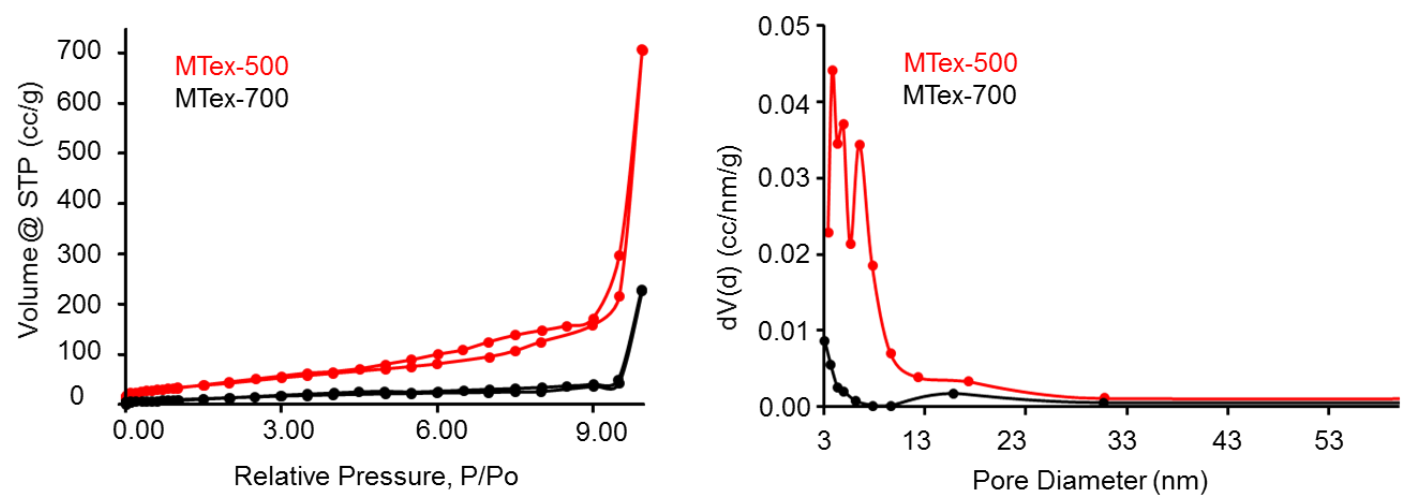

Figure S14: a, $\mathrm{N}_{2}$ adsorption isotherms b, pore size distribution plot of MTex-500 and MTex-700. 

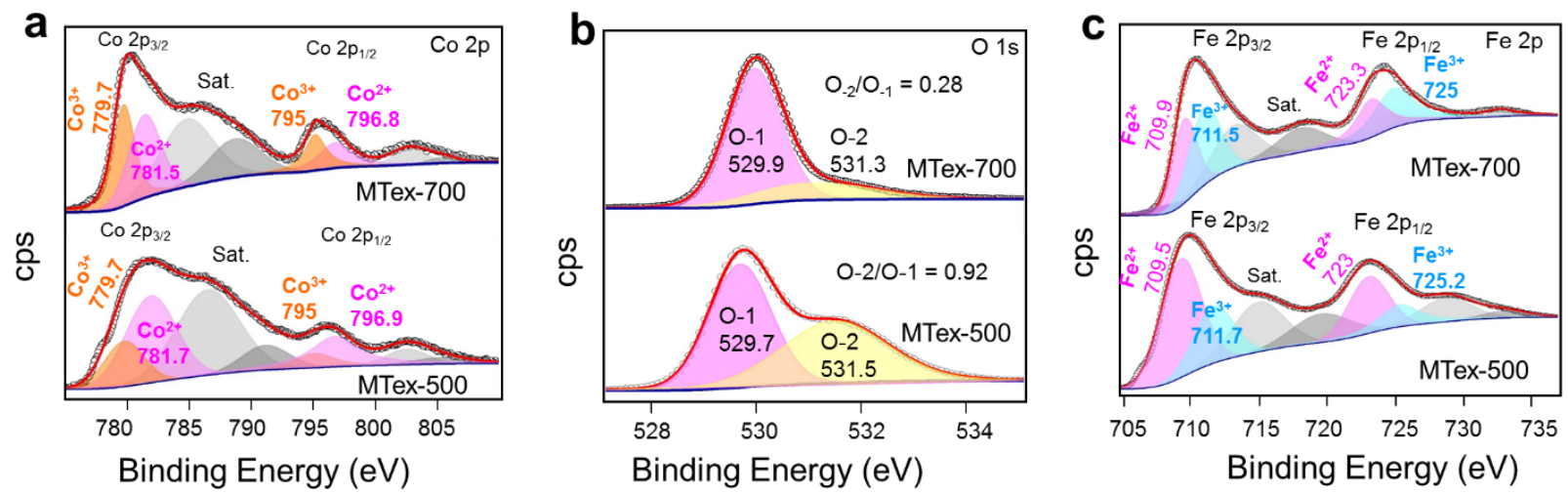

Figure S15. XPS characterization of as synthesized MTex-500 and MTex-700. a, Co 2p deconvoluted spectra for MTex-500 (bottom) showing the $\mathrm{Co}^{2+/} \mathrm{Co}^{3+}$ ratio $=0.98$, confirming the presence of more oxygen vacancy, while in MTex-700 (top) $\mathrm{Co}^{2+/} \mathrm{Co}^{3+}$ ratio $=0.52$. b, O $1 \mathrm{~s}$ deconvoluted spectra for MTex-500 (bottom) and MTex-700 (top) showing the presence of oxygen valances in MTex-500 (O-2/O-1 0.92) is much higher than MTex-700 (O-2/O-1 0.28), c, Fe 2p dencovoluted spectra of MTex-500 (bottom) showing $\mathrm{Fe}^{2+/} \mathrm{Fe}^{3+}=1.40$ while in MTex-700 (top) the $\mathrm{Fe}^{2+/} \mathrm{Fe}^{3+}=0.47$ 

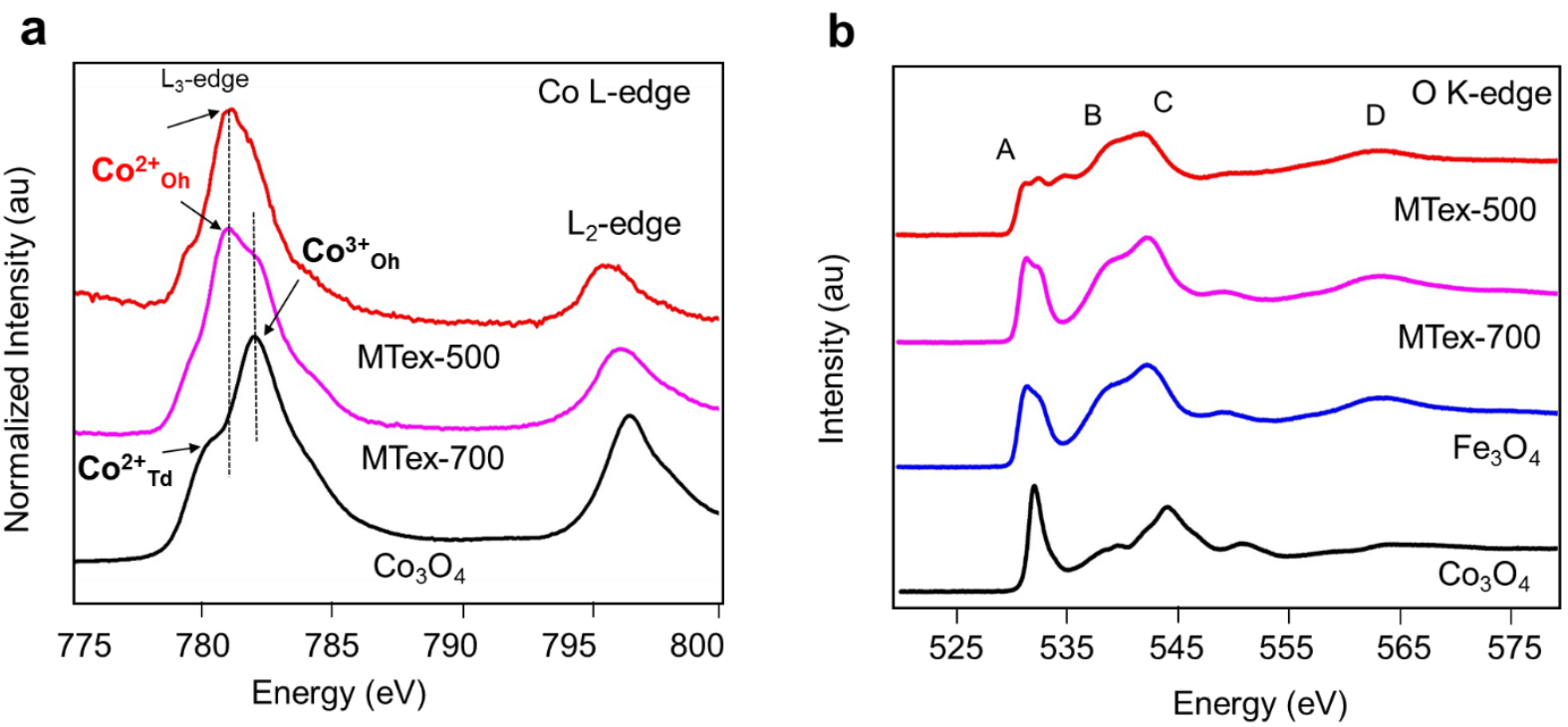

Figure S16. NEXAFS analysis. a, NEXAFS spectra of Co L-edge, The splitting of the $\mathrm{L}_{3}$ region at $~ 780$ eV in MTex-500 (red) corresponds to the $\mathrm{Co}$ (II) $\mathrm{O}_{\mathrm{h}}$ species while in MTex-700 both $\mathrm{Co}$ (II) $\mathrm{O}_{\mathrm{h}}$ and $\mathrm{Co}$ (III) $\mathrm{O}_{\mathrm{h}}$ species were observed. b, O K-edge spectra for MTex-500 (red) and MTex-700 (pink) compared with $\mathrm{Fe}_{3} \mathrm{O}_{4}$ and $\mathrm{Co}_{3} \mathrm{O}_{4} \mathrm{O} \mathrm{K}$-edge spectra. The first peak of the MTex-500 spectrum at $\sim 531 \mathrm{eV}$ became less intense, slightly broader and show multiplicity due to the different coordination environment in MTex-500. 
b

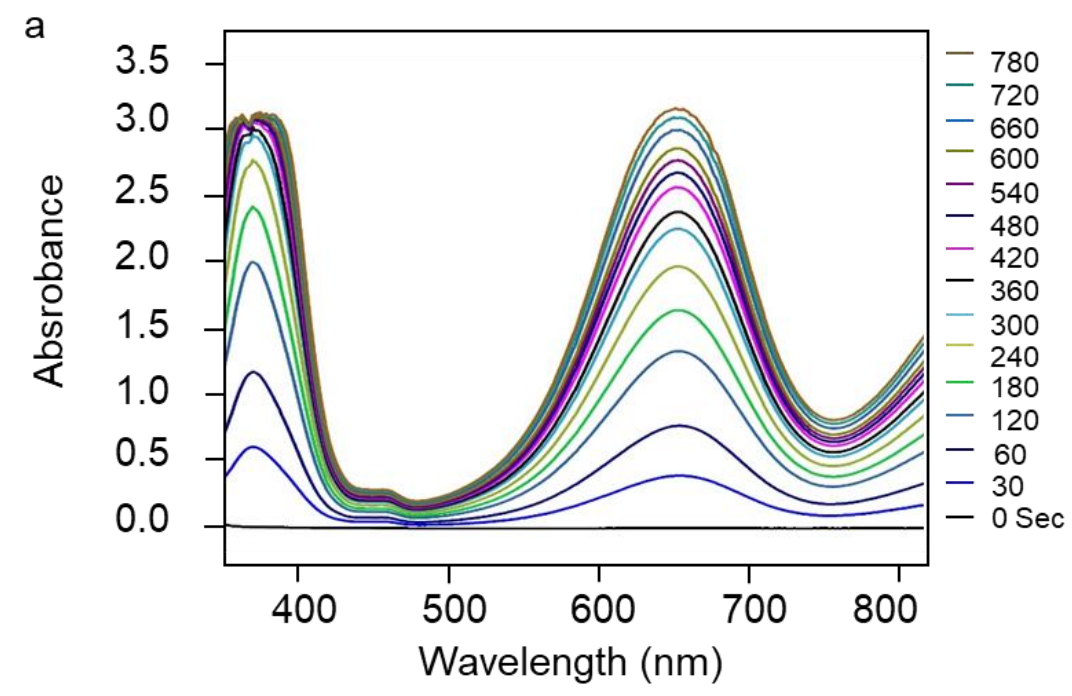

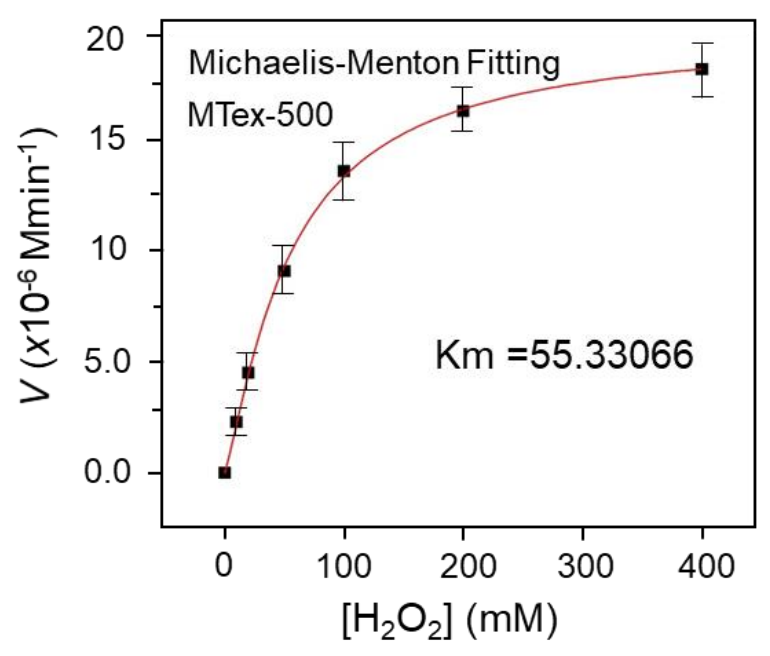

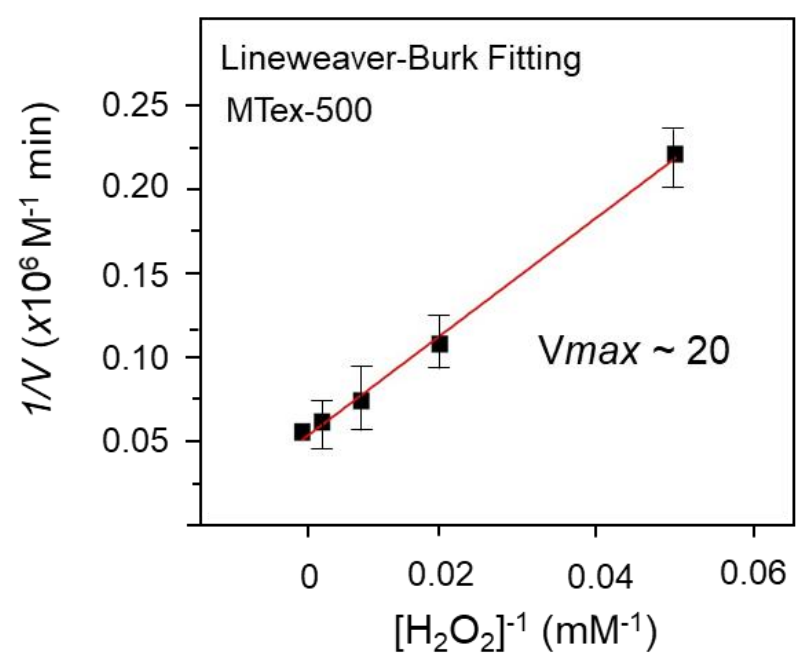

Figure S17. a, UV-Vis absorption spectra of oxidized TMB at different time, treated with MTex-500. b, Michaelis-Menten plot of MTex-500 catalyzed TMB oxidation at various $\mathrm{H}_{2} \mathrm{O}_{2}$ concentration keeping the TMB-concentration constant $(816 \mu \mathrm{M})$, Inset: The kinetic parameters Km. c, Lineweaver - Burk plots at different concentrations of $\mathrm{H}_{2} \mathrm{O}_{2}$, Inset: The kinetic parameters Vmax. 


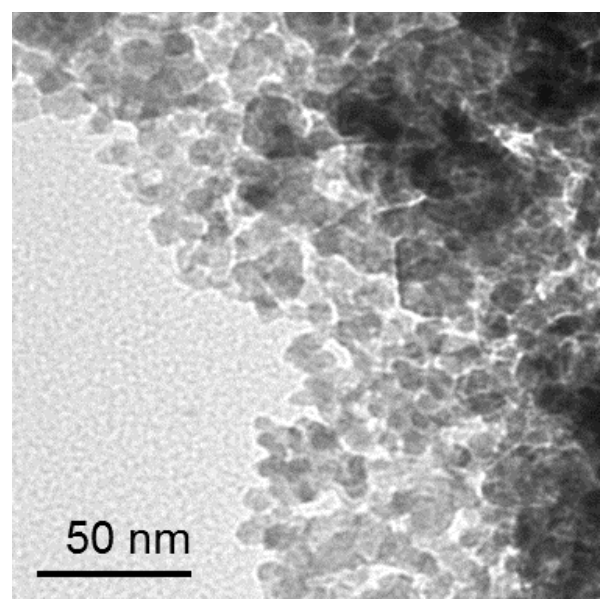

Figure. S18. TEM image of $\mathrm{CoFe}_{2} \mathrm{O}_{4}$ nanocrystals. 
a

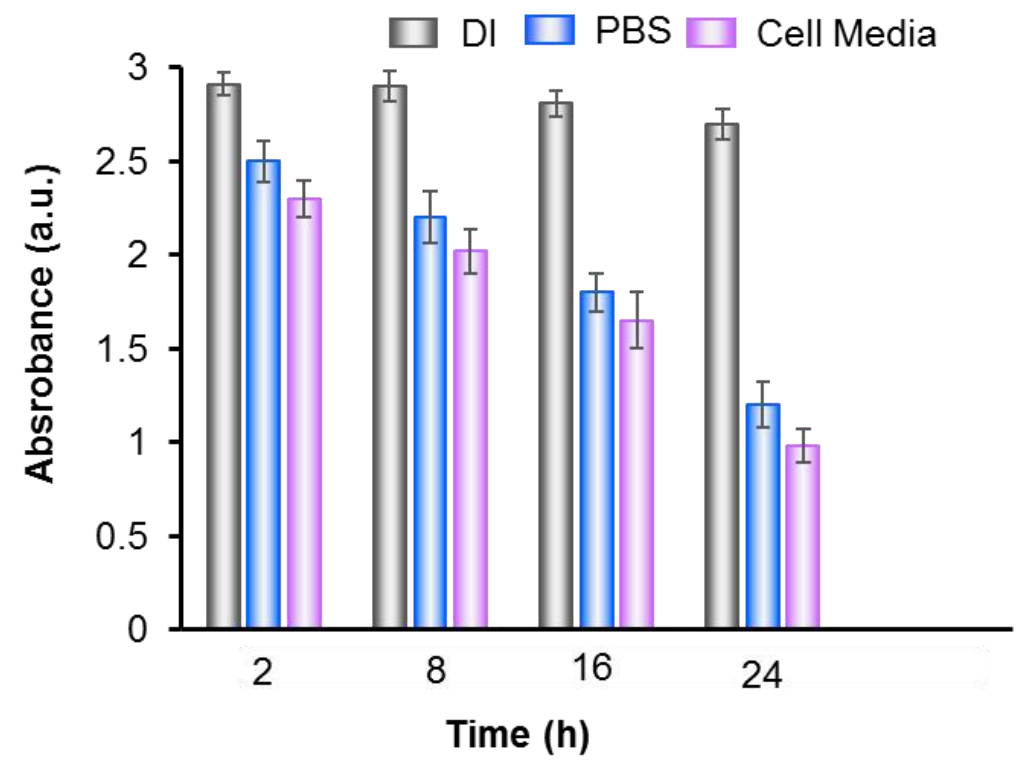

b

DI

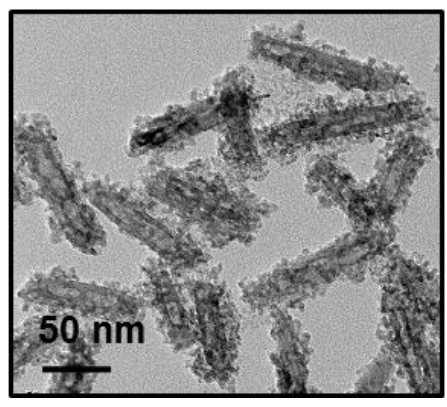

PBS

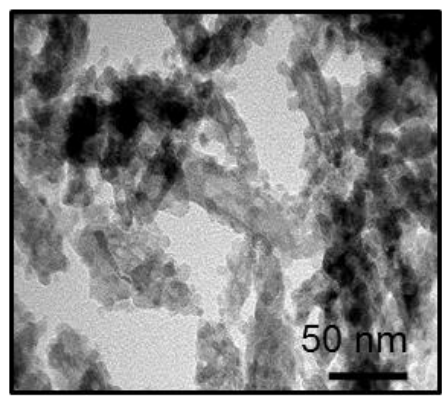

Cell Media

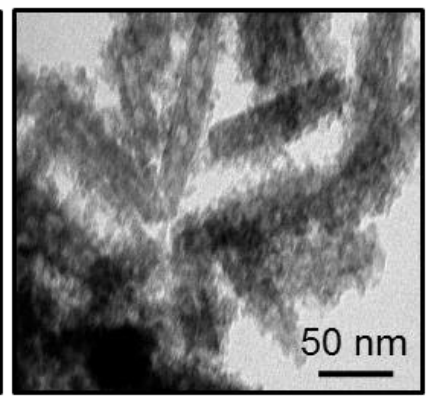

Figure S19: a, Time dependent catalytic activity of MTex-500 in different medium, b, TEM image of MTex-500 after 24h treatment in DI, PBS, and Cell Media. 

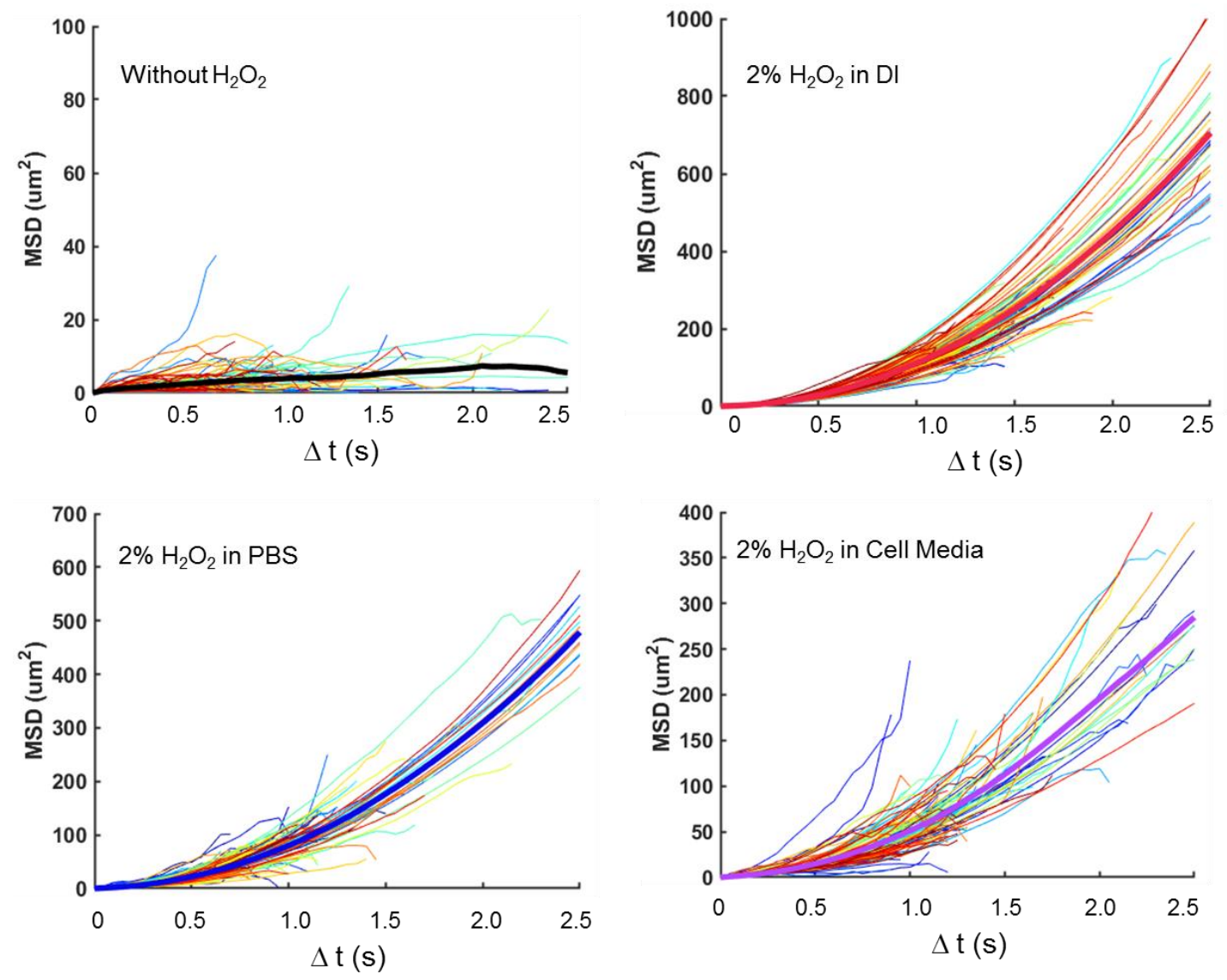

Figure S20: Statistical distribution of MSD Plots for 100 nanoparticles of MTex-500 with the averaged MSD function with and without the addition of $2 \% \mathrm{H}_{2} \mathrm{O}_{2}$ as fuel in DI and PBS buffer, cell media with addition of $2 \% \mathrm{H}_{2} \mathrm{O}_{2}$. 


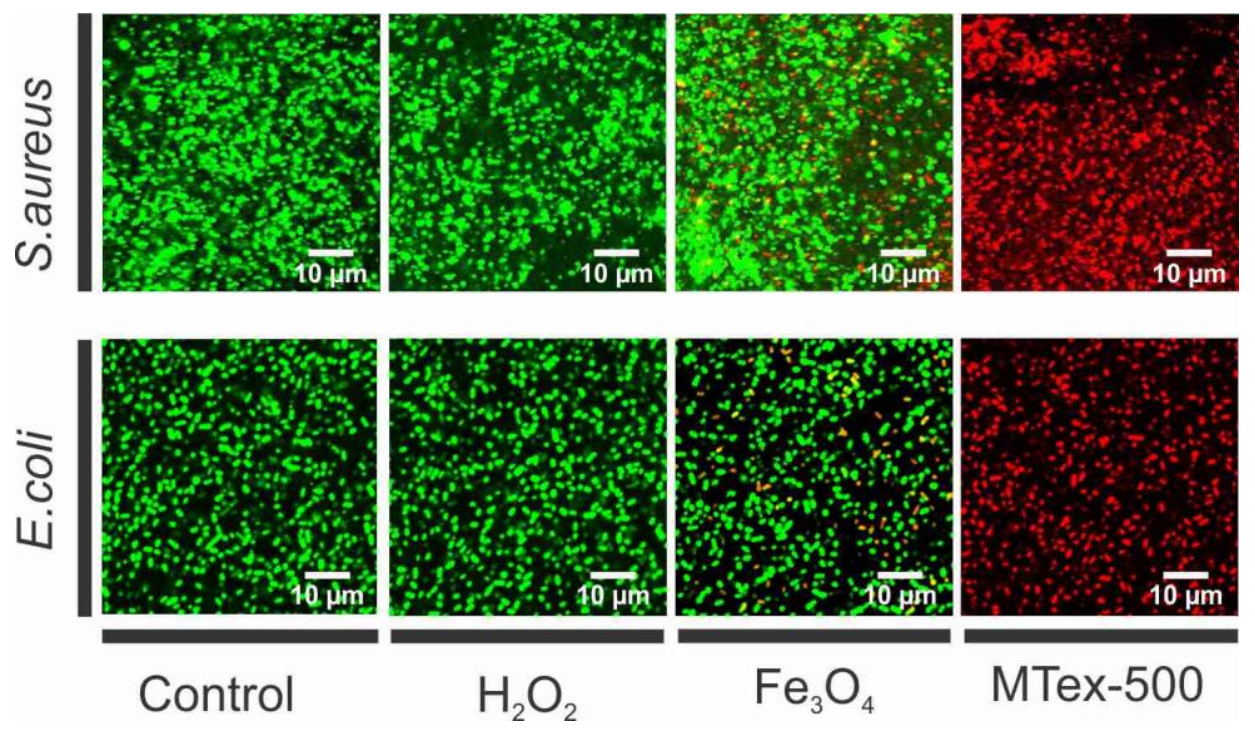

Figure S22. In vitro antibacterial activity of MTex-500. Live/dead (green/red) staining fluorescence images (scale bar, $10 \mu \mathrm{m}$ ) of $S$. aureus (top) and E. coli (bottom), suspensions incubated with MTex-500 $\left(500 \mu \mathrm{g} \mathrm{ml}^{-1}\right)$ and different control conditions for same time periods. 
S. aureus

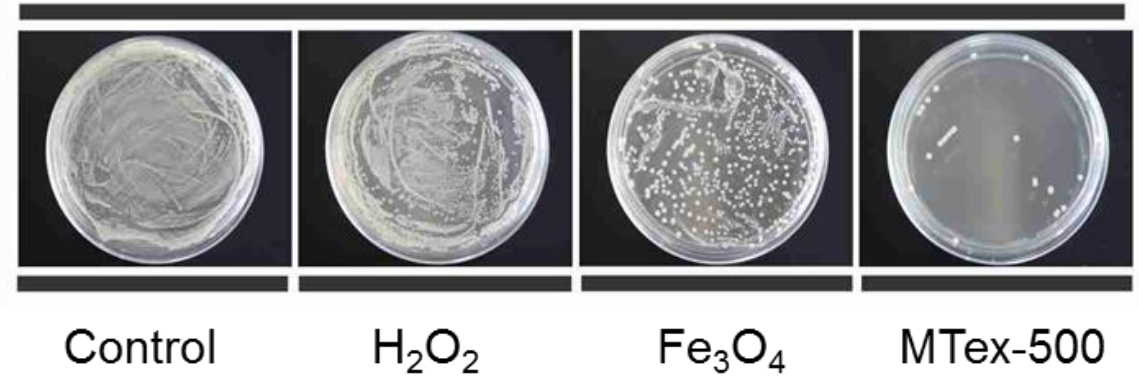

E. coli.

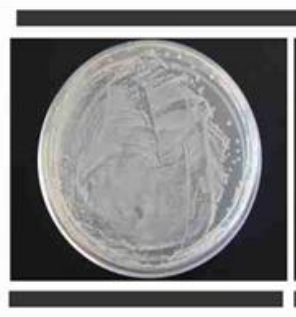

Control

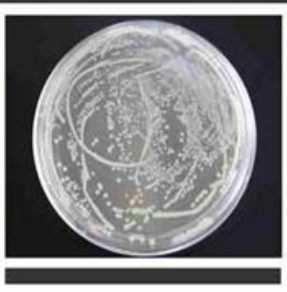

$\mathrm{H}_{2} \mathrm{O}_{2}$
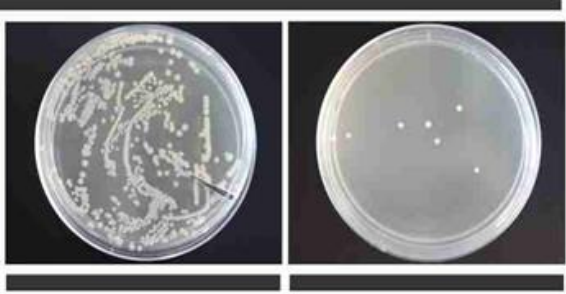

$\mathrm{Fe}_{3} \mathrm{O}_{4}$

MTex-500

Figure S22. In vitro antibacterial activity of MTex-500. The inactivation efficiency of different bacteria by MTex-500 was studied and compared with control. Agar plate photographs of two bacteria: S. aureus (top) and E. coli (bottom) after treatments by MTex-500 and different controls. The dilution fold for control, $\mathrm{H}_{2} \mathrm{O}_{2}, \mathrm{Fe}_{3} \mathrm{O}_{4}$ and MTex-500 were $10^{5}, 10^{3}, 10^{2}$ and 10, respectively. 


\section{S. aureus}
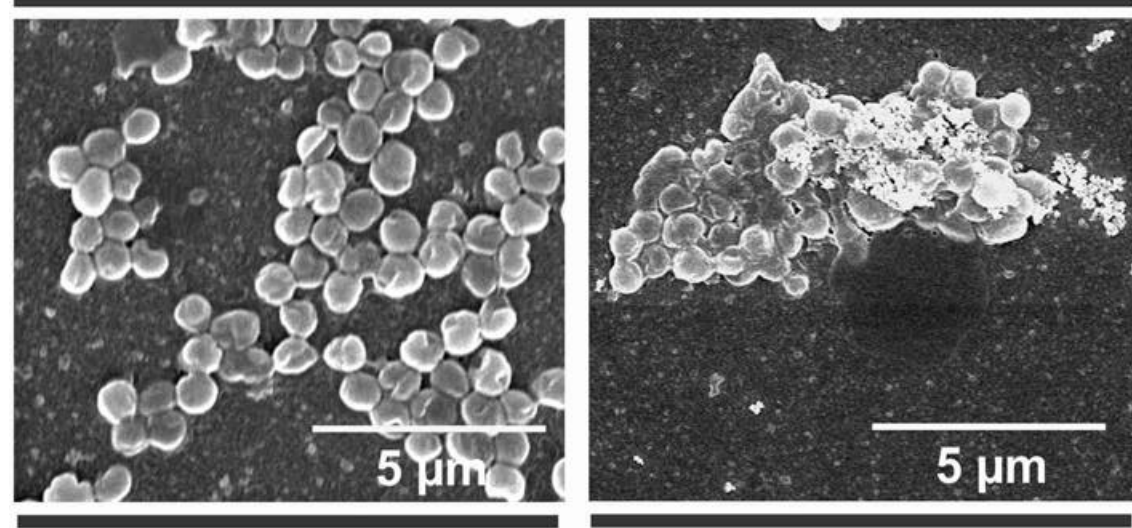

Control

MTex-500

\section{E. coli}

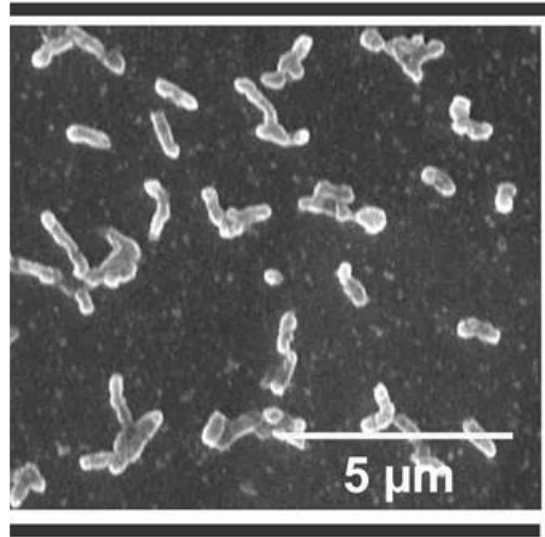

Control

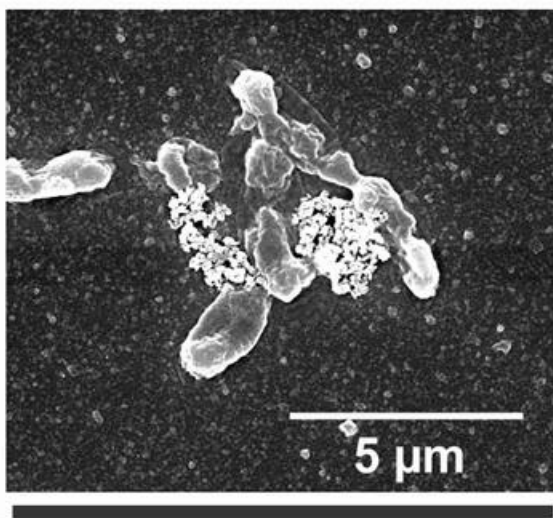

MTex-500

Figure S23. SEM images of planktonic S.aureus and E.coli before and after the treatment of MTex-500 and $\mathrm{H}_{2} \mathrm{O}_{2}$. 


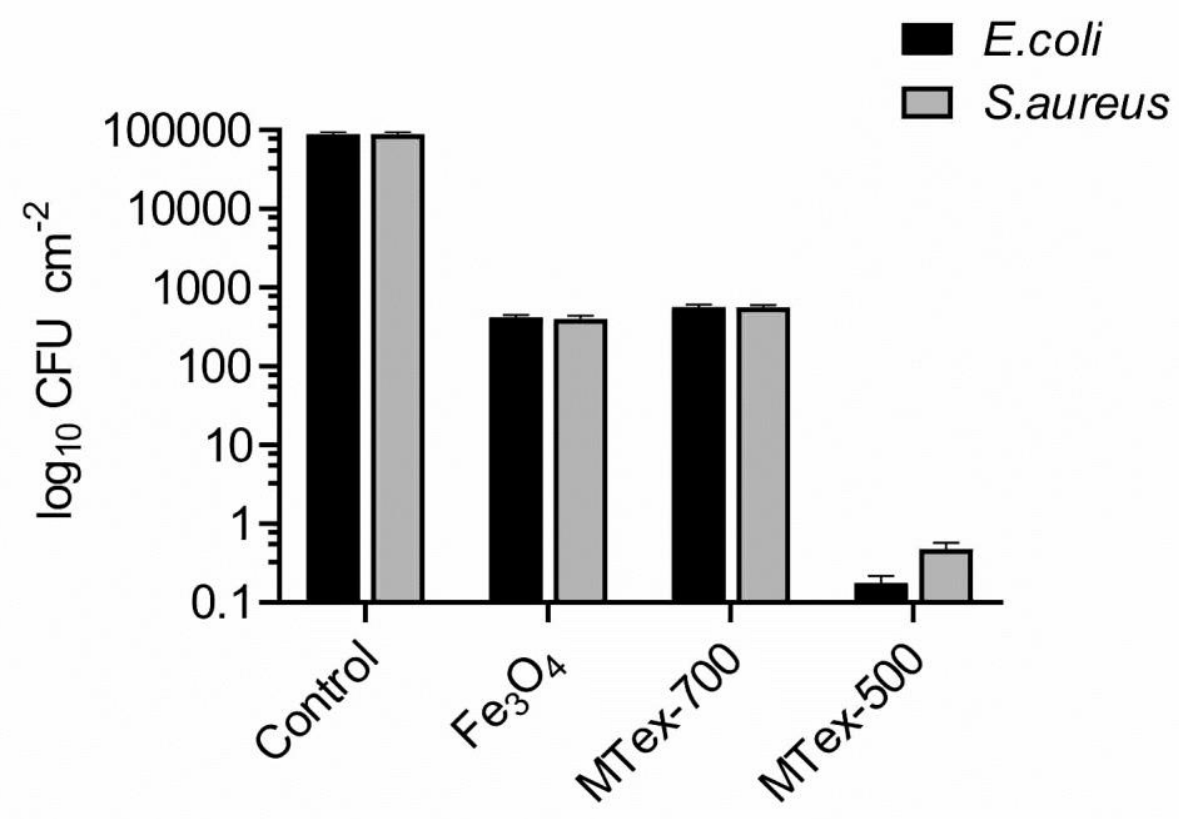

Figure S24: Biofilm removal $\left(\mathrm{CFU} \mathrm{cm} \mathrm{cm}^{-2}\right)$ studies for $S$. aureus and E. coli after treating with MTex-500 and MTex-700 $\left(1 \% \mathrm{H}_{2} \mathrm{O}_{2}\right)$ and different control conditions. Data are expressed as means \pm standard deviations over three separate experiments. To determine the CFU, Biofilm present on the plate was removed by sonication method: first, the media present in the plate was removed to discard the planktonic bacteria and replaced with the PBS. Then, water bath sonication was used for the homogenization, maintaining the condition 30-s pulse with $7 \mathrm{~W}$ output. Sample was collected in the tube and further analysis was done. To make sure, again the plate was sonicated for second time and remained biofilm was collected. 


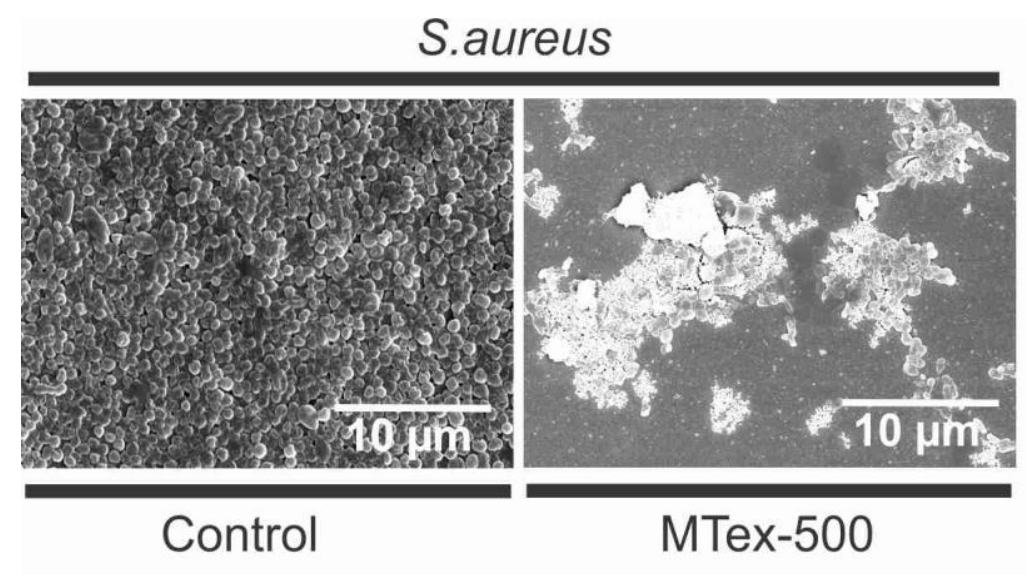

\section{E.coli}

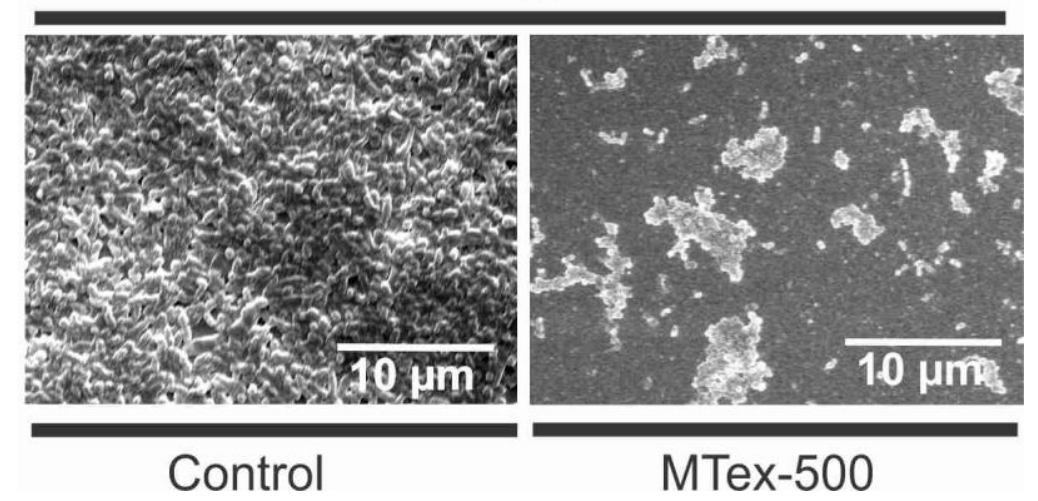

Figure S25. SEM images of biofilm of S.aureus and E.coli before and after the treatment of MTex-500. 
a

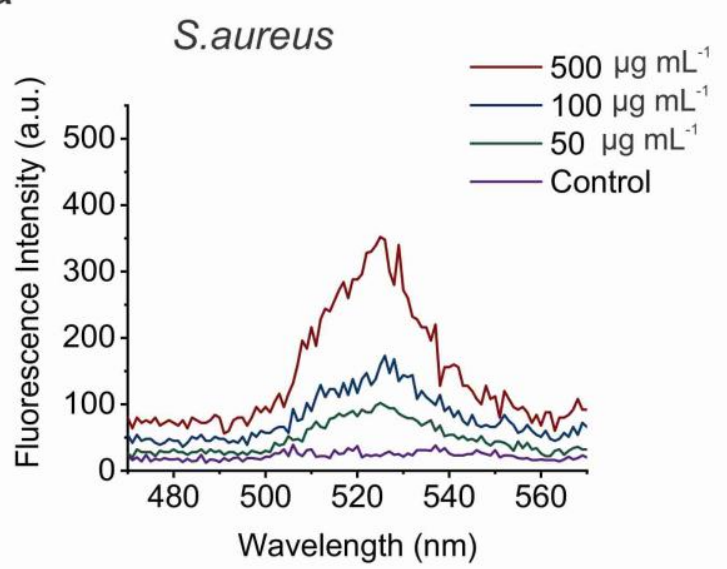

b
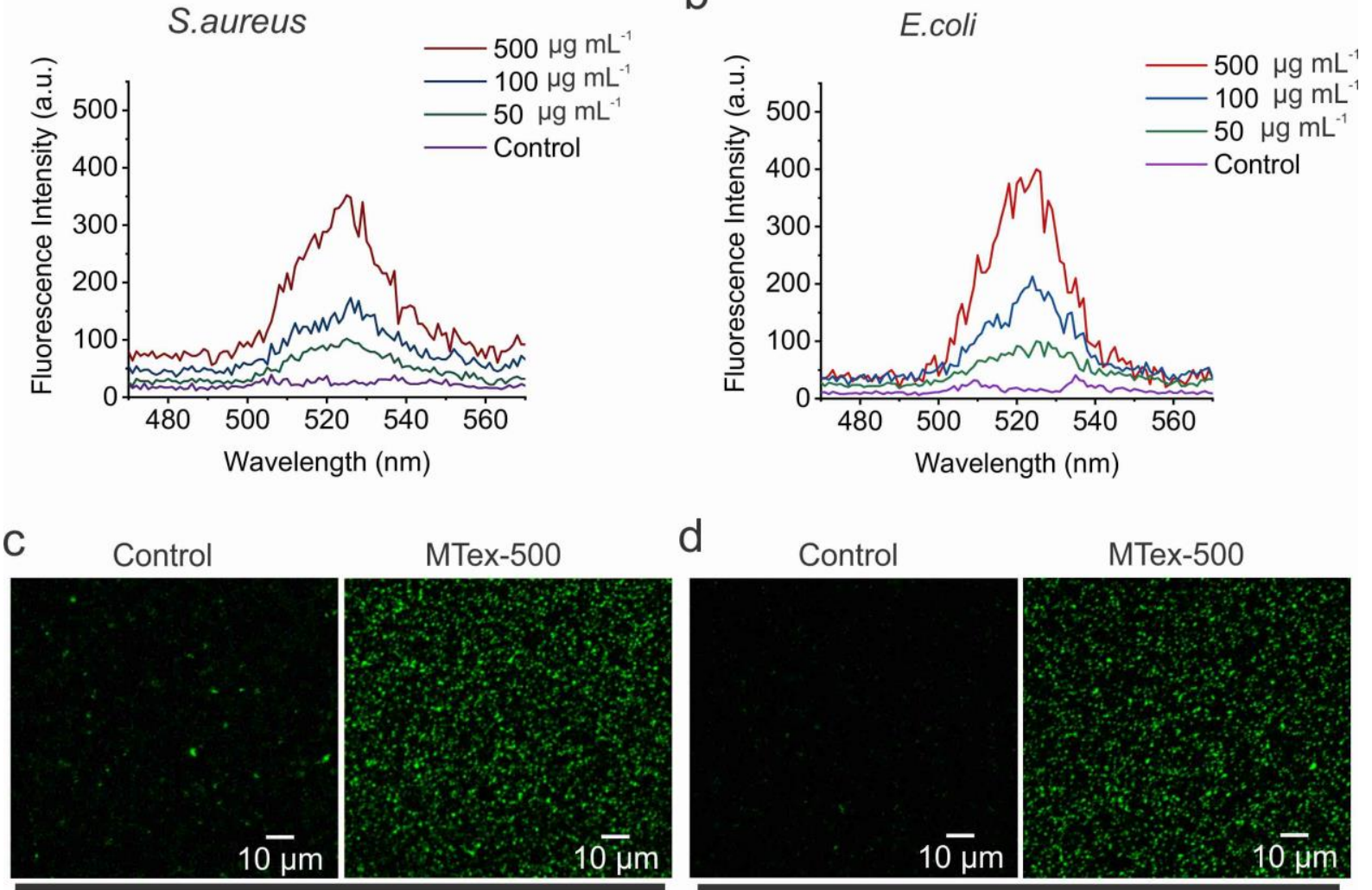

S.aureus d Control

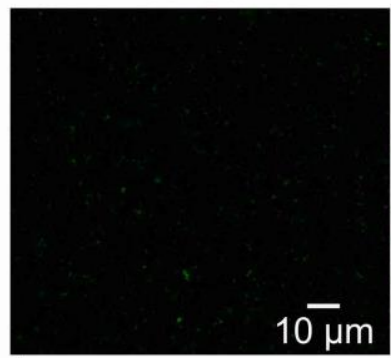

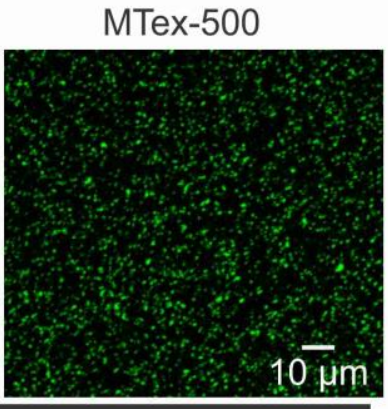

E.coli

Figure S26: a-b, Fluorescence spectra of DCFDA after treatment of S.aureus and E. coli with different concentration MTex-500 and untreated cells. c-d, Fluorescence microscopic images to confirm the production of ROS after the treatment of MTex-500 with S.aureus and E.coli followed by staining with $\mathrm{H}_{2}$ DCFDA. 

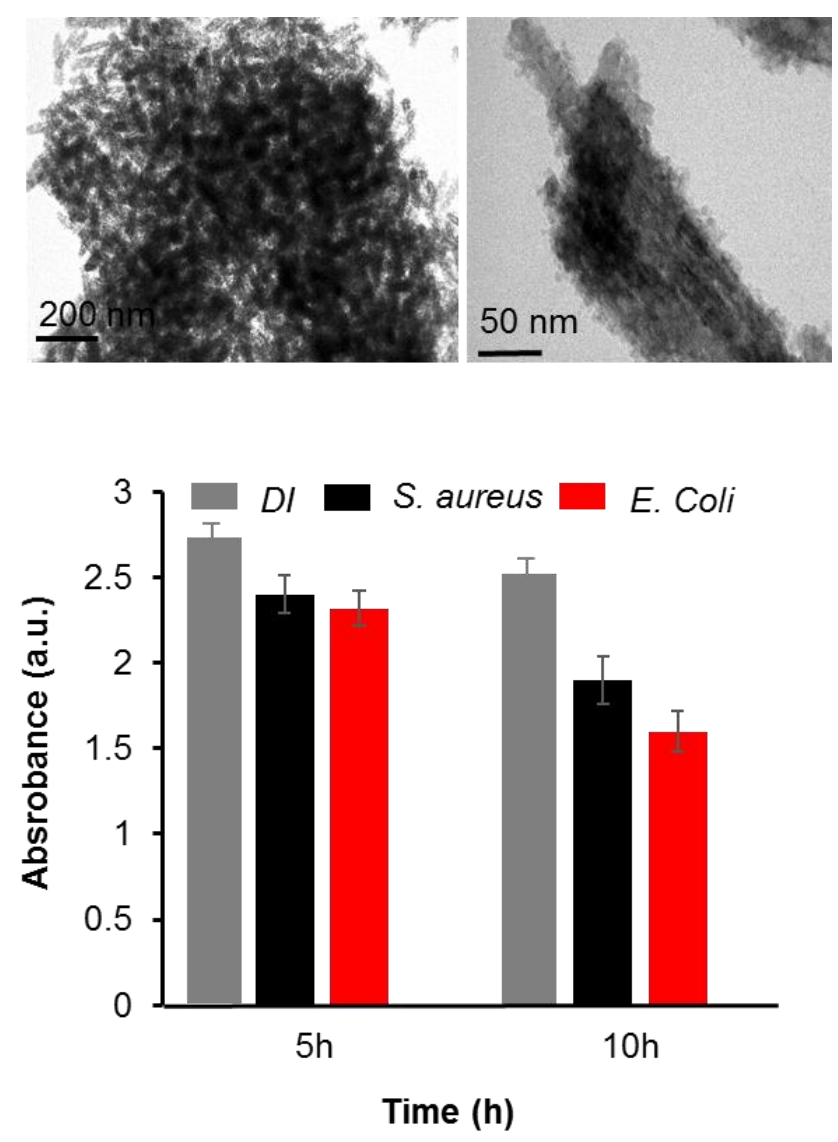

Figure S27: a, TEM images of MTex-500 recovered after $10 \mathrm{~h}$ incubation with S. aureus biofilm. b, and results of TMB-assay using MTex-500 after incubation with S. aureus and E. Coli biofilms and DI for different times. 


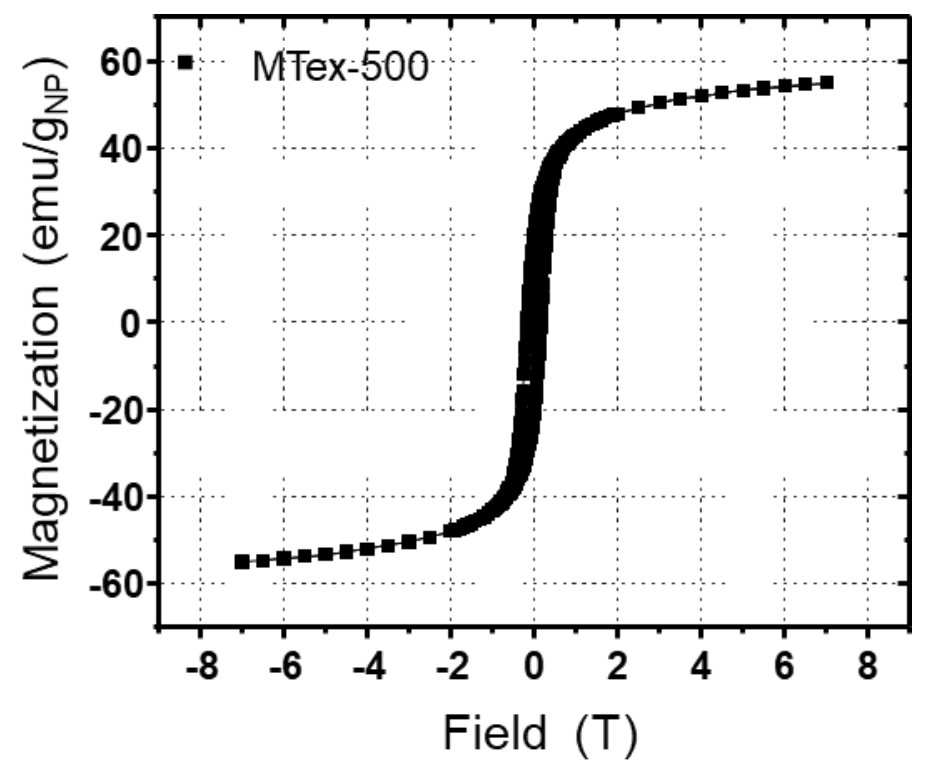

Figure S28. Magnetization curve of MTex-500 at room temperature. 
a

$\longrightarrow \begin{gathered}\text { Removal of } \\ \text { Biofilm clog }\end{gathered}$

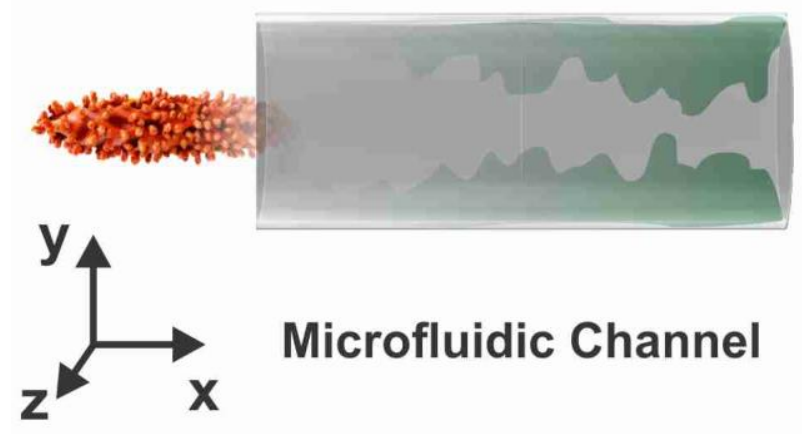

b

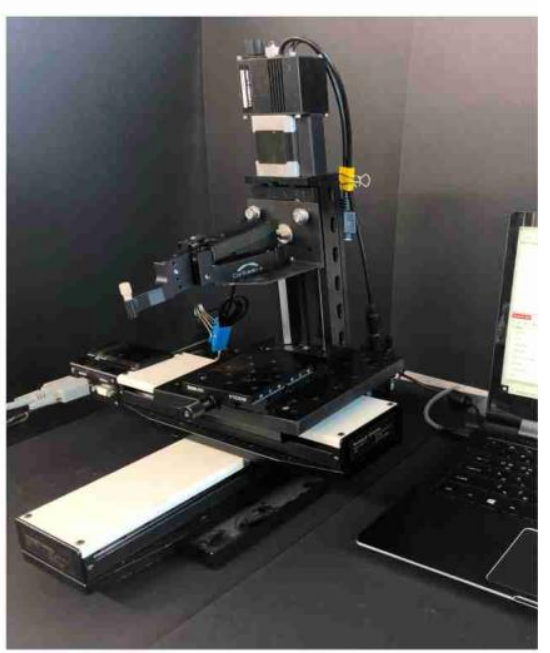

Figure S29. a, Pictorial representation of removal of biofilm inside the microfluidic device. b, real photo of instrument for controlling the movement of magnet. 
a

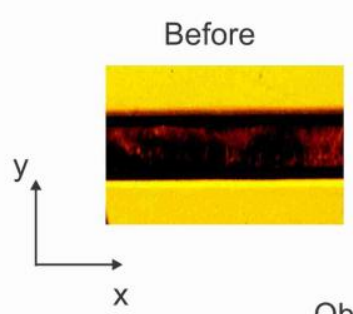

Oblique view

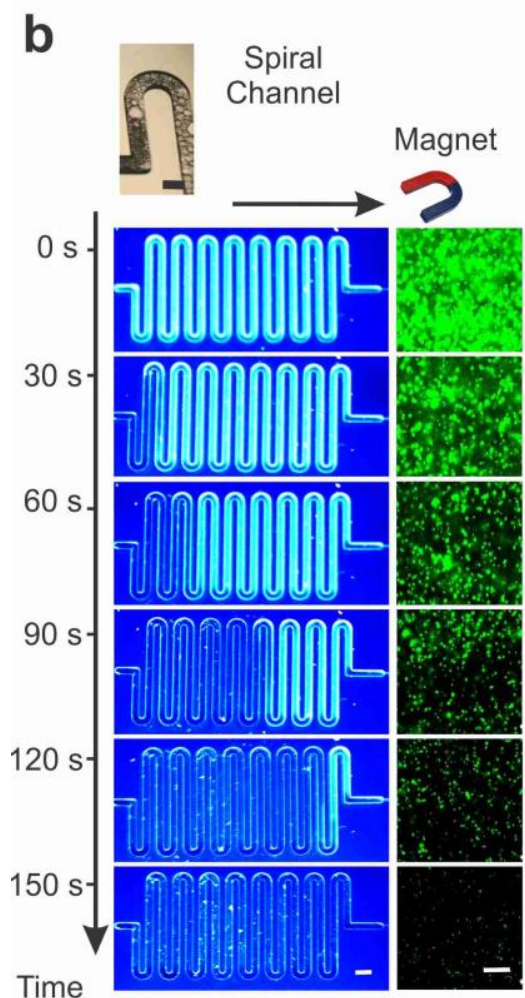

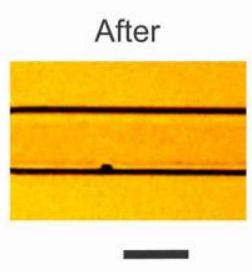

C
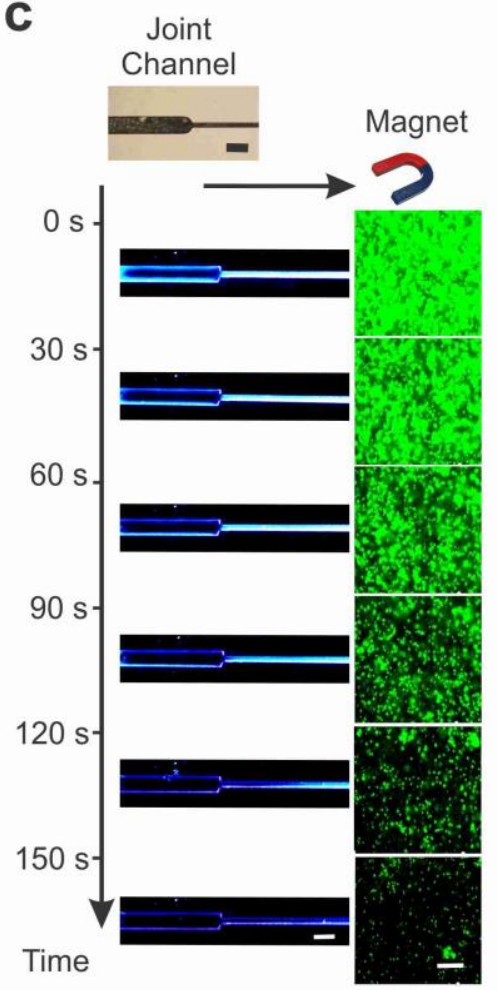

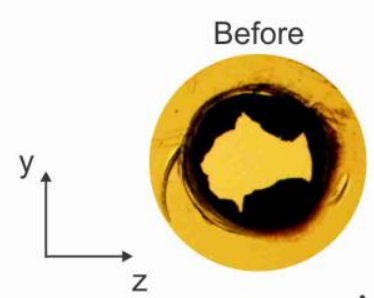

Axial view
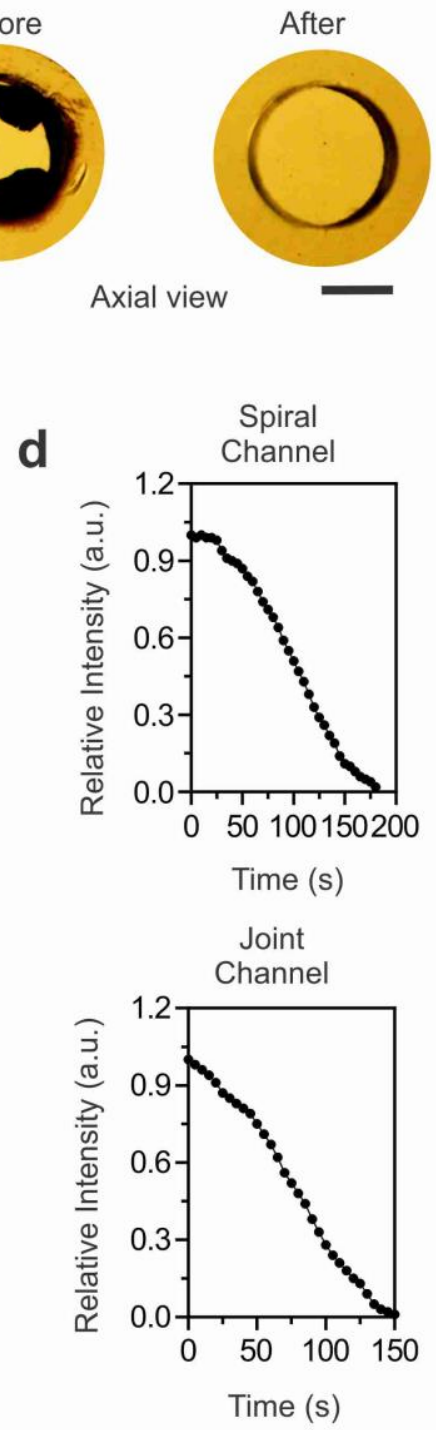

Figure S30. Magnetically-assisted antibiofouling of microchannels studies using MTex. a, Digital photographs showing oblique (scale bar $=4 \mathrm{~mm}$ ) and axial (scale bar $=2 \mathrm{~mm}$ ) views of microchannels before and after removing the biofilms. b-c, Digital photographs of spiral and joint microchannels (scale bar $=500 \mu \mathrm{m}$ ) with luminescent CCD images (scale bar $=1 \mathrm{~mm}$ ) and fluorescence images (scale bar $=10$ $\mu \mathrm{m})$, showing time-dependent magnetic sweeping of E. coli-clogged spiral and joint-type microchannels after treating with MTex-500 and $1 \% \mathrm{H}_{2} \mathrm{O}_{2}$. d, Quantitative analysis of relative fluorescence intensity from biofilms of $E$. coli in spiral and joint channels after treating with MTex-500 and $\mathrm{H}_{2} \mathrm{O}_{2}(1 \%)$. 
a

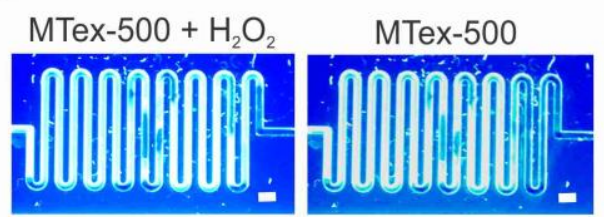

w/o Magnet

b

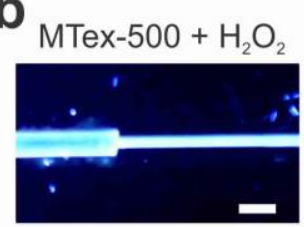

w/o Magnet with Magnet

MTex-500

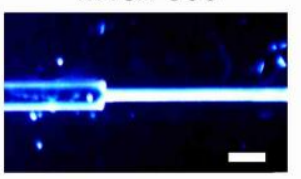

with Magnet
C

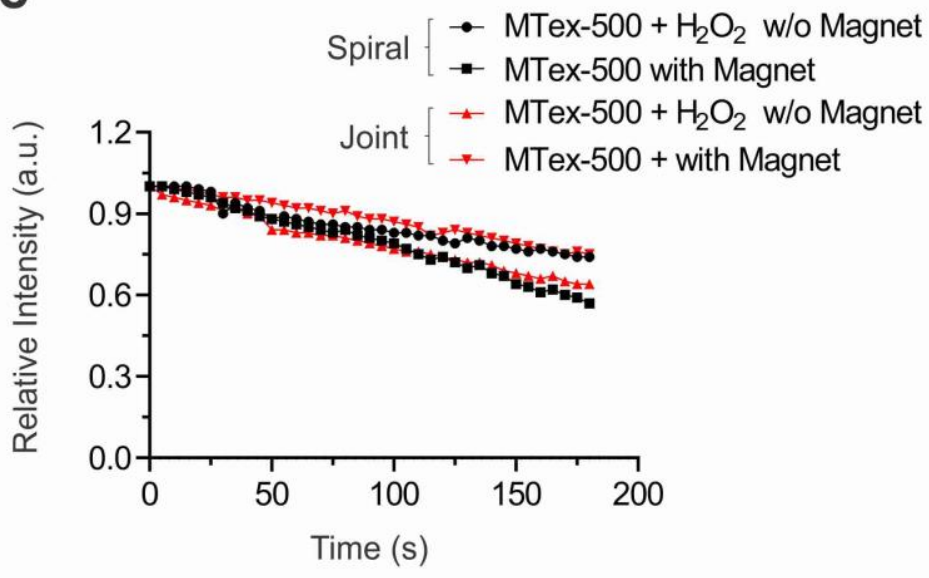

Figure S31. a, Captured imaged of microfluidic spiral channel in different condition. b, Captured imaged of microfluidic joint channel in different condition using MiniLumi E. c, calculated relative intensity during the process by using NIS software. 


\section{References}

1. Chen, M.; Tang, B.; Nikles, D. E. Preparation of iron nanoparticles by reduction of acicular $\beta$ FeOOH particles. IEEE Trans. Magn. 1998, 34, 1141.

2. Barreto, J.C.; Smith, G. S.; Strobel, N.H. P.; Mcquillin, P. A.; Miller, T. A. Terephthalic acid: a dosimeter for the detection of hydroxyl radicals in vitro. Life Sci. 1995, 56, 89.

3. Howse, J. R.; Jones, R. A.; Ryan, A. J.; Gough, T.; Vafabakhsh, R.; Golestanian, R. Self-Motile Colloidal Particles: From Directed Propulsion to Random Walk Phys. Rev. Lett. 2007, 99, 048102.

4. Liu,Y.; Naha, P. C.; Hwang, G.; Kim, D.; Huang, Y.; Simon-Soro, A.; Jung, H.-I.; Ren, Z.; Li, Y.; Gubara, S.; Alawi, F.; Zero, D.; Hara, A. T.; Cormode, D. P.; Koo, H.; Topical ferumoxytol nanoparticles disrupt biofilms and prevent tooth decay in vivo via intrinsic catalytic activity. Nat. Commun. 2018, 9, 2920. 